\title{
Promoting Inclusive Environments: In-group Organizational Endorsement as a Tool to Increase Feelings of Identity-Safety among Black Women
}

\author{
Dominque Burrows $^{1}$ (1) $\cdot$ Evava S. Pietri $^{2} \cdot$ India R. Johnson $^{3} \cdot$ Leslie Ashburn-Nardo $^{2}$ \\ Accepted: 14 October 2021 / Published online: 16 November 2021 \\ (c) The Author(s), under exclusive licence to Springer Science+Business Media, LLC, part of Springer Nature 2021
}

\begin{abstract}
Black women face unique and harmful biases because of their intersecting and multiple marginalized identities, which are different from those experienced by Black men and White women (Crenshaw in s. Cal. l. Rev., 65, 1467., 1991). As organizations work to create more inclusive environments for minoritized employees, it is important to test effective messaging and identity-safe cues (i.e., cues that enhance feelings of identity acceptance) for Black women. In the current research, we investigate a new identity-safe cue - in-group organizational endorsement. This technique involves two components: (a) learning about the successful experiences of a former Black female employee and (b) a persuasive message asserting that out-group employees can be supportive role models and mentors within the organization. In a pilot experiment $(N=182)$ and Study $1(N=236)$, Black female participants were more likely to believe role models and mentors can have different identities, to anticipate more identity-safety, and to have higher attraction to an organization that was endorsed by a former Black female employee compared to a White woman employee. Study $2(N=214)$ further demonstrated that in-group organizational endorsement was effective among Black female students early in their college career. Relative to a control group, Black female students in their $1^{\text {st }}-3^{\text {rd }}$ year who received the in-group endorsement intervention indicated higher identitysafety at their university and were more likely to pursue professional interactions with out-group members. For institutions that are actively working to promote inclusivity and pro-diversity norms among their employees, in-group organizational endorsement is one effective identity-safety signal for communicating such environments.
\end{abstract}

Keywords Black women $\cdot$ Gender $\cdot$ Race $\cdot$ Intersectionality $\cdot$ Identity-safety $\cdot$ Organizational $\cdot$ Inclusive environments Social identity theory $\cdot$ Persuasion

Black women possess at least two intersecting marginalized identities (i.e., gender and race). Consequently, Black women experience unique and harmful biases that differ from those faced by Black men and White women (Berdahl $\&$ Moore, 2006; Crenshaw, 1991). This distinctive mistreatment, which typically manifests as unwelcoming environments, results in Black women being underrepresented in many fields, including professional and academic positions

Dominque Burrows

db59@rice.edu

Rice University, Houston, USA

2 Indiana University-Purdue University Indianapolis, Indianapolis, USA

3 Butler University, Indianapolis, USA
(Cook \& Glass, 2014; Livingston et al., 2012; Turner et al., 2008). This lack of representation of Black women as well as the discrimination they experience due to their intersectional identity places Black women at a higher risk for social identity threat, or the concern over being devalued within an organization due to their identities (Steele et al., 2002). Specifically, this threat can ultimately lead to concerns about belonging in the organization (Murphy \& Taylor, 2012). Identity-safety cues (also referred to as diversity cues) are signals within institutions that suggest individuals' identities will be valued and help alleviate social identity threat and encourage belonging (Avery et al., 2004; Davies et al., 2005; Walton et al., 2015). For instance, past research has found that for Black women, observing a successful employee in a company or professor in a university who matches their gender and race acts as an effective identity-safety cue to 
promote trust and belonging in said company or university (Johnson et al., 2019; Pietri et al., 2018a).

A successful in-group member identity-safety cue may not be feasible for many companies or universities, which lack Black women employees (Bureau of Labor Statistics, 2018; Turner et al., 2008). When faced with this disparity, institutions can include pro-diversity messages in their recruitment materials (i.e., explicitly expressing their appreciation of diversity and women of color; Avery et al., 2013) in order to attract Black women applicants; however, Black women may not trust that this message is genuine (Wilton et al., 2020; Windscheid et al., 2016). In this article, we present three studies that aimed to address this problem by testing a new technique called in-group organizational endorsement. Integrating work from social identity theory and persuasion, this strategy involves two components: (a) learning about a former Black woman employee (i.e., a racial and gender in-group member) who had a successful experience in the organization and (b) a persuasive message asserting that out-group members can act as supportive role models and mentors. In the current research, we explored whether in-group organizational endorsement would function as an effective identity-safe cue to encourage Black women's belonging across multiple environments, including in companies and universities.

\section{Social Identity Threat}

Social identity threat occurs when people believe that their in-groups are devalued (Steele et al., 2002). Experiencing this threat can have a variety of harmful outcomes within organizational and educational contexts (e.g., burn out and disengagement, leaving a major; Banchefsky et al., 2019; Hall et al., 2015; Holleran et al., 2011; see Walton et al., 2015 for review). For instance, worrying that an important identity will be devalued can lead to concerns about belonging and being accepted by fellow employees or other students (Good et al., 2012; Purdie-Vaughns et al., 2008; Walton \& Cohen, 2007). When prospective employees worry they will not belong in an organization, they are less attracted to the organization and avoid job openings in the company (Pietri et al., 2019). Moreover, belonging and threat concerns about conferences lead students to avoid these career enhancing events (Murphy et al., 2007). Once established in an institution, individuals worrying about belonging are less likely to approach others and network with them, further restricting professional growth (Martiny \& Nikitin, 2019).

Individuals can be a part of multiple in-groups and, thus, have multiple identities that can be devalued and threatened in an organization (Abrams \& Hogg, 1999; Crenshaw, 1991). Specifically, intersectionality theory posits that multiple group identities such as gender and race cannot be added together to be understood, but instead, the combination creates distinct stereotypes and experiences that are inherently different from the stereotypes associated with a singular identity (Cole, 2008; Crenshaw, 1991). For instance, because Black women do not represent the prototypical Black individual (i.e., a Black man) or woman (i.e., a White woman), they experience a form of invisibility bias (Coles \& Pasek, 2020; Purdie-Vaughns et al., 2008), whereby they go unseen and unheard, and have their ideas misattributed to others (Sesko \& Biernat, 2010). Moreover, Black women face unique stereotypes that are not attributed to White women nor Black men (Galinsky et al., 2013; Rosette et al., 2016). Specifically, Black women are often perceived as overly dominant and "angry," but not competent, which is perceived as incompatible with prestigious positions, such as leadership (Rosette \& Livingston, 2012; Rosette et al., 2016).

The invisibility bias, unique stereotypes, as well as pervasive sexism and racism within professional and educational settings lead to the experience of double jeopardy or double disadvantage for Black women in organizations (Hancock, 2007; Purdie-Vaughns et al., 2008). For example, within workplace settings, Black women report having to work harder than their White women colleagues to be perceived as legitimate, having their ideas mistakenly attributed to their male and White colleagues, and experiencing more harassment than both Black men and White women (Berdahl \& Moore, 2006; Cortina et al., 2013; Settles, 2006; Williams, et al., 2014). Black women students also experience more discrimination and unfair treatment than White women and Black men students (Eaton et al., 2020). Thus, it makes sense that Black women students often report higher social identity threat and lower belonging compared White women and Black male counterparts (Casad et al., 2019; Rainey et al., 2018). Importantly, Black women's concerns about their identities being devalued in institutions are centered in reality because their voices often ignored (Sesko \& Biernat, 2010) and they experience compounding mistreatment (Eaton et al., 2020; Rosette \& Livingston, 2012).

\section{Addressing Social Identity Threat and Promoting Inclusive Environments}

To address Black women's identity-threat concerns, it is critical that companies and universities work to address the compounding mistreatment experienced by Black women and promote inclusive climates (Chen, 2017; Downey et al., 2014; Li et al., 2019; Nishii, 2013). In particular, companies should enact policies and trainings to ensure the equitable treatment of all employees and facilitate a diversity-valuing organizational culture (Avery \& McKay, 2010; Bezrukova et al., 2016; McKay et al., 2008; Onyeador et al., 2021). Moreover, universities should create reward structures that highlight faculty who promote welcoming environments 
(Moss-Racusin et al., 2021) and require inclusive teaching and mentoring workshops for instructors (Moss-Racusin et al., 2016; Pfund et al., 2009, 2015).

While working to foster these inclusive environments through policies and trainings, it is also crucial that organizations signal to Black women that their identities will be valued to further assuage social identity threat concerns. One way for organizations to achieve this goal is through the introduction of identity-safety cues, which are cues that suggests that one's identity will be valued in an environment (Avery et al., 2004; Davies et al., 2005; Walton et al., 2015). Other employees within an organization or instructors within a university can signal identity-safety and alleviate social identity threat concerns by either being role models or mentors. A role model is a successful employee that individuals identify with and aspire to be like in the future (Gibson, 2004). As such, role models can protect against social identity-threat (Dasgupta, 2011; Stout et al., 2011). Thus, exposure to successful and relatable in-group role models can increase belonging and enhance motivation to seek out career opportunities in potentially threatening environments (Asgari et al., 2011; Buunk et al., 2007; Pietri et al., 2019; Stout et al., 2011). In contrast to role models, other employees can function as mentors for Black women. Mentors are experienced employees who provide consistent guidance and support to newer employees (Gibson, 2004; see also, Fowler et al., 2007). There are multiple benefits associated with receiving mentorship in organizations including higher job satisfaction and positive career outcomes (e.g., higher salaries, receiving promotions; Allen et al., 2004; Eby et al., 2008; Misra et al., 2017; Noe, 1988). Moreover, in college, having supportive mentors can promote women students' academic achievement (Blake-Beard et al., 2011; Downing et al., 2005). Of importance, mentors can also act as identity-safety cues to promote women's sense of belonging (Dennehy \& Dasgupta, 2017).

Although White women are gender-based in-group members, Black women's perceptions are influenced by their multiple marginalized identities (Cole, 2009; Warner, 2008), and past work found that racial in-group members were critical for sparking identity-safety among Black women (Pietri et al., 2018a). For example, past research has found that Black women anticipated the most belonging and trust in a company when they learned about a successful Black woman employee, followed by a Black male employee, whereas learning about a successful White woman employee did not encourage belonging for Black women (Pietri, et al., 2018a, b; see also Johnson et al., 2019). Unfortunately, the disparity of Black men and women in professional and academic positions (Bureau of Labor Statistics, 2018; Turner et al., 2008) may result in Black women not having access to a successful employee or instructor who shares their racial in-group identity. However, when organizations actively work to facilitate inclusive environments through the implementation of multiple policies and trainings, they may create pro-diversity norms among their employees and attract employees who value diversity (Homan et al., 2007, 2010; Nishii, 2013; Onyeador et al., 2021). Thus, organizations that are successful in establishing pro-diversity norms are well positioned to enact recruitment strategies that seek to attract prospective employees from marginalized groups.

In an effort to demonstrate their commitment to marginalized employees, organizations and universities have utilized diversity management tactics such as posting diversity statements (i.e., statements signaling that they value racial diversity) on their company/college websites (Avery et al., 2013; Jayne \& Dipboye, 2004; Point \& Singh, 2003). However, this strategy has the potential to backfire and Black women may not trust the authenticity of a message delivered by the organization or a current White employee (Highhouse et al., 2002; Wilton et al., 2020; Windscheid et al., 2016). Thus, an important question is what institutions can do to signal their employees care about supporting Black women, and promote Black women's identity-safety when a company or university still lacks racial diversity? We aim to address this issue by testing a new strategy that institutions can implement called in-group organizational endorsement.

\section{In-Group Organizational Endorsement}

Broadly, in-group organizational endorsement involves an in-group former employee or student disclosing her successful experience in organization with supportive out-group role models and mentors. This technique builds off recent work, which demonstrated that Black women participants trusted that a White woman employee cared about supporting Black women after a Black coworker endorsed the White employee as an ally (Johnson \& Pietri, 2020). Rather than endorsing a specific individual, the current strategy involves endorsing a whole organization. Critically, we operationalize in-group organizational endorsement as comprising two important components. The first component encompasses learning about an in-group member who has succeeded in the organization. Differing from past work (e.g., Johnson et al., 2019; Pietri et al., 2018a), we assert that this in-group member does not need to be currently at the institution, but rather can be a former employee or student who had a successful past experience (e.g., gained beneficial skills while working as summer intern). People who have worked in organizations are seen as credible sources of information (Fisher et al., 1979), particularly when they recount their individual experiences in the organization (Van Hoye \& Lievens, 2007). Thus, knowing that a racial in-group member (i.e., a Black woman former employee or student) had a positive experience within an organization may encourage feelings of identity-safety among Black women. 
The second component of in-group organizational endorsement involves a persuasive message asserting that out-group employees can function as role models and mentors and care about helping the in-group. We expect that this general message will be beneficial regardless of the source. Specifically, we anticipate that learning a company has supportive out-group employees will spark more identitysafety relative to no message even when the source is a racial out-group member (i.e., White woman). However, drawing from classic literature on in-group persuasion, we also predict that Black women will be more likely to believe that role models and mentors can have non-matching identities when that message comes from a Black woman compared to a White woman (Allen, 1975; Clark \& Maass, 1988a, b; Insko et al., 1985). Indeed, when a message is relevant to the in-group, people will pay more careful attention to and be more persuaded by a message when it is delivered by an in-group member than out-group member (Esposo et al., 2013; Knippenberg et al., 1994; Mackie et al., 1990, 1992; Walker et al., 2009). Taken together, past research from both the organizational (Van Hoye \& Lievens, 2007) and persuasion (Esposo et al., 2013; Mackie et al., 1990) literature suggests that learning about a Black women former employee who had positive experiences with out-group role models and mentors may be a powerful strategy to encourage Black women's identity-safety.

\section{Current Research}

Across one pilot experiment and two experiments, we tested whether in-group organizational endorsement functioned as an efficacious identity-safety cue to promote a sense of belonging among Black women. We first examined whether in-group organizational endorsement would signal identity-safety at the beginning of the recruitment process in a company setting (Pilot Study and Study 1). Specifically, in Study 1, we tested the two components of in-group endorsement separately and explored whether this strategy was most effective when a former Black woman intern had a positive experience at an organization and conveyed that the organization had supportive outgroup mentors and role models. Using a longitudinal design, in Study 2 we explored whether in-group endorsement promoted Black women students' persistent identity-safety at their university and encouraged students to seek out potential role models/mentors with different identities.

We predicted that a message from a Black woman (i.e., racial in-group member) would be more effective at increasing beliefs that role models and mentors can have different identities relative to a message from a White woman (i.e., racial out-group member) or no message (Hypothesis 1a). Moreover, we anticipated that compared to receiving no information or reading about a White woman's experiences, learning about a Black woman's positive experience with supportive out-group role models and mentors at the organization (i.e., both in-group organizational endorsement components) would result in higher anticipated identity-safety at the organization, stronger interest in working at the organization, and a higher likelihood of networking with out-group members (Hypothesis $1 b$ ).

We also tested each component of in-group organizational endorsement separately and anticipated that both components would be important. That is, we expected that reading about a former Black female employee's success in an organization would be more effective at increasing beliefs that role models and mentors can have different identities and identity-safety and interest in organization relative to learning about the success of a White woman (Hypothesis 2a). Furthermore, we predicted that having any former employee (i.e., a White or Black woman) describe supportive out-group role models and mentors in a company would lead to stronger beliefs that role models/ mentors can have different identities and higher identitysafety and interest in organization relative to not reading this message (Hypothesis 2b). Thus, we predicted that combining both components of in-group organizational endorsement would function as the most effective identitysafe cue.

\section{Study 1}

Prior to the first experiment, we conducted a pilot experiment to provide an initial test of the experimental materials. (See Supplement A in the online supplement for detailed information regarding the pilot study methods and findings). The findings from the pilot study indicated that compared to learning about the experiences of a White woman, when Black women participants learned that a Black woman had a positive experience in a company, they were more likely to believe that role models and mentors could have different identities in a company, anticipated more identity-safety in the organization, and had higher intentions to pursue a job the company.

A limitation of our pilot study, however, was that we did not test the two components of in-group organizational endorsement (i.e., presence of an in-group member and organizational endorsement) separately and thus, could not determine whether these two components were both important and have the predicted additive effect. To address this limitation, in Study 1, we assigned participants to learn about a past intern who had a successful experience at a company and was either a White or Black woman. In addition to manipulating the race of the intern, we also manipulated whether the past intern conveyed the message that outgroup members can act as role models and mentors within the organization. We predicted there would be significant 
main effects for both race and message condition and no significant interactions between conditions.

We also recognized that highlighting a previous Black woman intern may lead to perceptions that the organization typically hires Black women and that there is racial and gender diversity in the organization, which would promote identity-safety (Avery et al., 2004; Pietri et al., 2018a). To address this possibility, we measured beliefs about the number of women employees, Black employees, and Black women employees currently working at the organization. If our manipulation influenced these beliefs, we planned to control for these perceptions in our analyses. Of note, for all experiments, our research protocol was reviewed and approved by an institutional review board (IRB) for compliance with standards for the ethical treatment of human participants prior to data collection.

\section{Method}

\section{Participants}

A priori power analyses with G*Power (Faul et al., 2007) indicated that to replicate our findings between the White woman and Black woman intern condition on identity-safe from the pilot study $(d=0.36)$ and detect a significant effect at $p<.05$, at $80 \%$ power, we would need a sample of 244 participants. We recruited 291 Black women working on Amazon's Mturk for $\$ 1.50$ to take part in Study 1 to account for exclusions due to attention checks. (Participants who completed the pilot study were prevented from taking part in the current experiment.) We ran this experiment through "TurkPrime" hosted on CloudResearch (Moss \& Litman, 2018), and only advertised our study to Black women. Seven participants were excluded for not completing our measure assessing perceptions of the percentage of Black employees (as described below we ended up controlling for this variable in our main analyses). These seven participants did not vary across condition $\mathrm{X}^{2}(3, N=291)=0.29, p=.962$. In addition, 48 participants were removed for failing attention checks (which are describe under procedure), resulting in a final sample of 236 participants. Of these 236 participants, $27.1 \%(N=64)$ had their high school diploma/GED, 19.5\% (46) had a degree from a 2-year college, $41.5 \%(N=98)$ had a 4-year college degree, $11.8 \%$ (28) had a master's or Professional degree. Most of the sample was employed least part time, $84.7 \%$ (200).

This study included a race (Black woman versus White woman) by message condition (supportive mentorship message vs no mentorship message) design (Black woman/ supportive mentorship message: $n=58$; Black woman/no mentorship message: $n=63$; White woman/ supportive mentorship message: $n=49$; White woman/no mentorship message: $n=66$ ). We used chi-square analyses to determine whether there was a significant difference in the number of participants excluded for failing attentions checks across the experimental conditions. A significant difference was found, $\mathrm{X}^{2}(3, N=280)=16.55, p=.001$, such that participants in the White woman supportive mentorship message condition failed their manipulation checks at significantly higher rates compared to the three other conditions (Black woman supportive mentorship message $=13$; Black woman no mentorship message $=7$; White woman supportive mentorship message $=20$; White woman no mentorship message $=4$ ). Importantly, the Black women conditions (the Black woman supportive mentorship message and the Black woman no mentorship message) had relatively equivalent levels of exclusion, $\mathrm{X}^{2}(1, N=141)=2.00, p=.157$.

A power sensitivity analyses using $\mathrm{G}^{*}$ Power (Faul et al., 2007) indicated that with a between-subjects ANOVA, to find a significant effect of condition with 1 degree of freedom in the numerator and four conditions, at $80 \%$ power, we were adequately powered to find a small to medium $(f=0.18)$ effect size at $p<.05$.

\section{Procedure}

We advertised the current study as being interested in participants' impressions of companies, and participants were told they would be evaluating and providing their perceptions of an organization. We designed a website and organizational newsletter for a fictitious company called Uptown Consulting, which was presented as a business-to-business technology firm. Participants first saw this website, which included information on the services Uptown Consulting offered such as IT management and accounting. Information on this website was kept neutral, with no diversity cues (i.e., there were no pictures of employees or diversity statements). Next, participants read a "where are they now" company newsletter that highlighted the experience of woman named Mary Jones who was previously an intern at the company. The woman was described as an executive consultant at another fictitious company (Axil Consulting), who attributed her success partly to her previous internship at Uptown Consulting. Participants were randomly assigned to one of four conditions where they read about a past intern who was either Black or White and who either conveyed a supportive message that out-group members can act as role models and mentors or did not explicitly deliver this message. The photos used for the Black and White woman intern were pilot tested prior to use in the primary experiments. (See Supplement B in online supplement for detailed information on the photos).

In the supportive mentorship message conditions, participants read a newsletter in which Mary Jones (presented as Black or White) highlighted her positive experience at Uptown Consulting, specifically focusing on how influential 
her mentors and role models were in shaping her success during that time period. She also gave advice, which was to be open to mentors and role models of different identities. Thus, the newsletter promoted the message that out-group role models and mentors within the organization can be supportive and beneficial. In the no mentorship message conditions, participants read a newsletter in which Mary Jones (presented as Black or White) discussed how the internship, in general, provided her with positive work experience to aid her future career success, but did not indicate the company had supportive mentors and role models. She advised readers to treat internships as though they were actual jobs to help prepare for joining the workforce. (See Supplement $\mathrm{C}$ in the online supplement for detailed information on the experimental stimuli used to manipulate organizational endorsement).

After reviewing this newsletter, participants completed the attention check questions. These questions assessed whether participants remembered the occupation, current place of employment, and advice given by Mary Jones, which depended on the experimental condition. (See Supplement $\mathrm{D}$ in the online supplement for the attention check items). Following completion of the attention check items, participants completed the outcome measures and then were thoroughly debriefed. Upon completing the study, participants were compensated $\$ 1.50$ via their MTurk accounts.

\section{Measures}

\section{Beliefs that Role Models and Mentors Can Have Different Identities}

We developed two measures for the purpose of this study to assess beliefs that role models can have different identities and beliefs that mentors can have different identities at Uptown Consulting. (See Supplement E and F in the online supplement for detailed information regarding the items used to assess mentorship beliefs and the factor analyses supporting the structure of this measure). To respond to these items, participants were first given the definition of a role model (see Dasgupta, 2011; Morgenroth et al., 2015), and then rated their agreement with four items indexing their beliefs that role models can have different gender/racial identities (e.g., "After reading about Mary's experiences, I believe that role models at Uptown Consulting could be inspiring even when they are not Black women"), using a 5-point Likerttype scale, ranging from 1 (strongly disagree) to 5 (strongly agree). (Cronbach's $\alpha=0.84, M=4.0, S D=0.7$ ). They were then given the definition of a mentor (see Allen et al., 2004; Ragins \& Cotton, 1999) and indicated their agreement with five statements measuring their beliefs that mentors can have different gender/racial identities (e.g., "After reading about Mary's experiences, I believe that a mentor, who is not a Black woman, could help me achieve my professional goals"), using the same 5-point scale (Cronbach's $\alpha=0.76$, $M=4.0, S D=0.6)$. Because beliefs about role models and mentors were strongly correlated $(r(234)=0.70, p<0.001)$, we created $\mathrm{z}$-scores for the beliefs about role models and beliefs about mentor's indices, and then averaged these $\mathrm{z}$-scores to create a composite measure of beliefs that role models and mentors can have different identities.

\section{Identity-Safety}

To operationalize anticipated identity-safety we used an index that researchers have previously employed among samples of Black women (see Pietri et al., 2018a), Latina women (see Pietri et al., 2019), and Black women college students (see Johnson et al., 2019). Specifically, participants completed a four-item measure of trust and comfort (e.g., "I think I could be myself at Uptown Consulting") adapted from Purdie-Vaughns et al. (2008), 5-point Likerttype scale, ranging from 1 (strongly disagree) to 5 (strongly agree) (Cronbach's $\alpha=0.88, M=3.7, S D=0.7$ ). Drawing from Good et al. (2012) and Walton and Cohen (2007)'s belonging scales, participants also completed an eight-item measure of belonging (e.g., "At Uptown Consulting, I would feel respected), using the same 5-point scale (Cronbach's $\alpha=0.85, M=3.6, S D=0.6)$. Consistent with past research measuring identity-safety (see Johnson et al., 2019; Pietri et al., 2018a, 2019), and the high correlations between belonging and trust and comfort in the current study, $r$ [234] $=0.80, p<0.001$, we standardized the scores for belonging and trust and comfort and created a composite index to assess anticipated identity-safety at Uptown Consulting. (See Supplement G in the online supplement for detailed information on the items comprising the measure of identity-safety).

\section{Attraction to Uptown Consulting}

To measure interest in working at Uptown Consulting, participants completed a five-item measure of job pursuit intentions (e.g., "I would accept a job offer from Uptown Consulting") adapted from Highhouse et al. (2003), 5-point Likert-type scale, ranging from 1 (strongly disagree) to 5 (strongly agree) (Cronbach's $\alpha=0.89, M=3.8, S D=0.7$ ). We also examined organizational attractiveness utilizing a five-item measure (e.g., "For me, Uptown Consulting would be a great place to work") adapted from Highhouse et al. (2003), using the same 5-point scale (Cronbach's $\alpha=0.90$, $M=3.8, S D=0.8)$. These measures were strongly correlated, $r(233)=0.82, p<0.001$. Thus, we created a $\mathrm{z}$-score composite of these two measures to assess attraction to Uptown 
Consulting. (See Pietri et al., 2019 for similar z-score measure used among Latina women.)

\section{Racial Identity Perceptions}

To assess racial diversity and gender diversity perceptions at Uptown Consulting to determine whether the presence of a Black woman intern influences perceptions that the company was diverse, we asked participants the following three questions: (1) "What percentage of Uptown's employees do you think are racial or ethnic minorities?" (2) "What percentage of this company do you think are women?" (3) "What percentage of Uptown Consulting's employees do you think are Black women?" All three of these questions were measured using a sliding scale from $0-100$ percent.

\section{Results}

The means and standard deviations for each of the dependent variables across the conditions are presented in Table 1.

\section{Preliminary Analyses}

We first ran a between-subjects ANOVA with past intern race (Black or White past) and message condition (supportive mentorship message or no mentorship message) predicting each of the three perceptions of diversity (see Table 1). For perceptions of women and Black women employees at Uptown consulting, there were no significant main effects of race or message condition, $p s>0.334)$. However, for perceptions of Black employees at the organization, there was a significant main effect of race, $F(1,232)=3.99, p=.047$, $\eta_{\mathrm{p}}{ }^{2}=0.017$, such that those in the Black woman intern condition $(M=35.9, S D=17.2)$ perceived the company as having a significantly higher percentage of Black employees compared to those in the White woman intern condition $(M=30.9, S D=18.6)$. As a result, we controlled for perceptions of the percentage of Black employees at Uptown in all subsequent analyses to ensure that any effect of race condition was significant above these perceptions.

\section{Primary Analyses}

Beliefs that role models and mentors can have different identities was significantly correlated with identity-safety $(r$ [334] $=0.49, p<0.001)$, attraction $(r[334]=0.54$, $p<0.001)$, and identity-safety was also significantly related to attraction $(r[334]=0.85, p<0.001)$.

For all the primary outcome variables, we conducted two tests. First, we ran between subjects ANCOVAs with intern race and message condition as the independent variables, while controlling for perceptions of the racial diversity in the organization. Because we predicted that the Black woman intern communicating a supportive mentorship message would be most effective, we ran a second ANCOVA comparing this condition to the other three conditions combined (i.e., Black woman with no mentorship message, White woman with supportive mentorship message, White woman with no mentorship message), again controlling for perceptions of racial diversity in the organization.

\section{Beliefs that Role Models and Mentors Can Have Different Identities}

For beliefs that role models and mentors at the company can have different identities, there were significant main effects of race, $F(1,231)=11.68, p=.001, \eta_{\mathrm{p}}{ }^{2}=0.048$, and message condition $F(1,231)=10.55, p=.001, \eta_{\mathrm{p}}{ }^{2}=0.044$, and no significant interaction between race and message condition, $F(1,231)=1.02, p=.315, \eta_{\mathrm{p}}{ }^{2}=0.004$. Supporting Hypothesis $2 \mathrm{a}$ and $2 \mathrm{~b}$, participants were more likely to believe that role models and mentors can have different identities when they read about a Black woman intern $(M=0.2$, $S D=0.7)$ relative to a White woman intern $(M=-0.2$, $S D=1.0)$, and when the intern conveyed the supportive mentorship message $(M=0.2, S D=0.9)$ compared to when the intern did not deliver this message $(M=-0.2, S D=0.9)$. Participants who read about the Black woman asserting the company had supportive out-group members reported the highest perceptions that role models and mentors at the company can have different identities. Indeed, a follow-up analysis demonstrated that participants in the Black woman supportive mentorship message condition were more likely to believe that role models and mentors can have different identities $(M=0.4, S D=0.7)$ compared to participants in the other three conditions combined $(M=-0.1, S D=1.0)$, $F(1,233)=10.94, p=.001, \eta_{\mathrm{p}}{ }^{2}=0.045$.

\section{Identity-Safety}

For anticipated identity-safety at the organization, there were significant main effects of race, $F(1,231)=6.68, p=.010$, $\eta_{\mathrm{p}}{ }^{2}=0.028$, and message condition, $F(1,231)=4.56$, $p=.034, \eta_{\mathrm{p}}{ }^{2}=0.019$, and no significant interaction between race and message condition, $F(1,231)=0.02, p=.904$, $\eta_{\mathrm{p}}{ }^{2}<0.001$. Thus, providing support for Hypotheses 2a and $2 b$, even when controlling for perceptions of racial diversity, participants reported more anticipated identity-safety when they read about a Black woman intern $(M=0.2, S D=1.0)$ relative to a White woman intern $(M=-0.2, S D=0.9)$, and when the intern delivered the supportive mentorship message $(M=0.2, S D=0.8)$ relative to no mentorship message $(M=-0.1, S D=1.0)$. Participants anticipated the most identity-safety at the company when they read about a Black woman who asserted that the company had supportive 


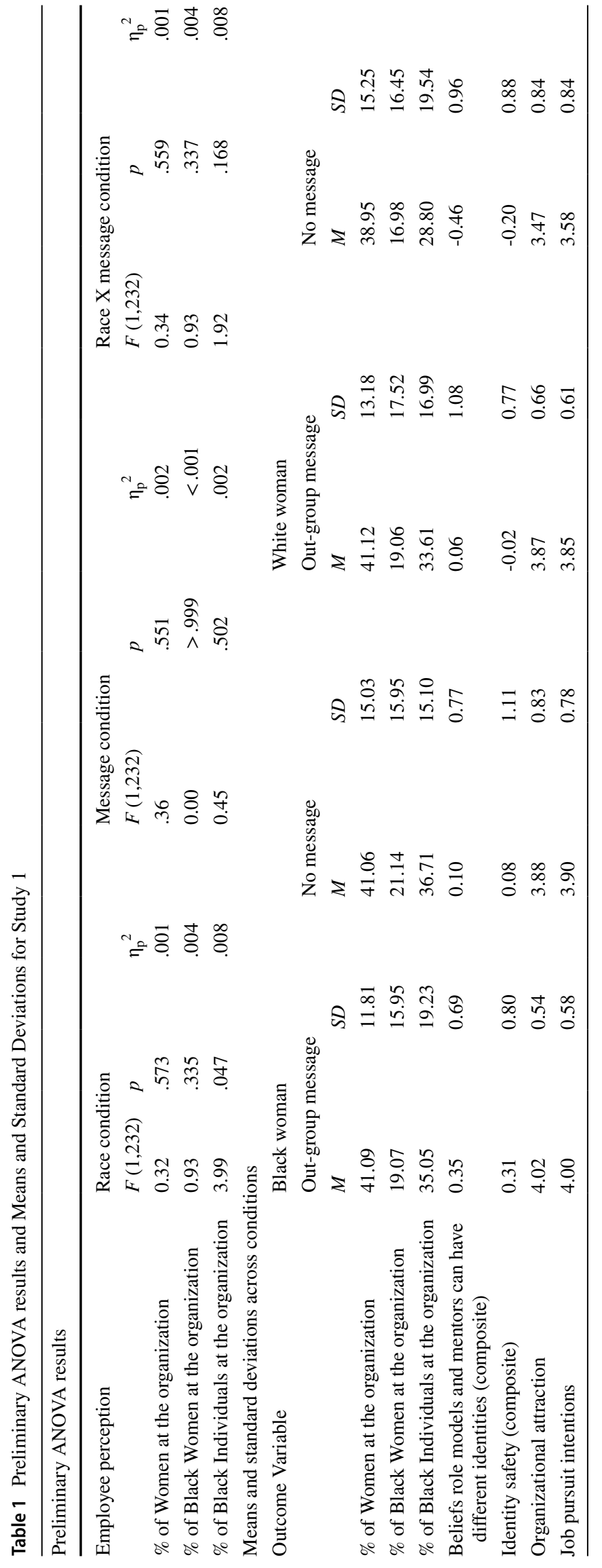


out-group mentors and role models; and reported significantly higher identity-safety $(M=0.3, S D=0.8)$ compared to the three other conditions combined $(M=-0.1, S D=1.0)$, $F(1,233)=8.05, p=.005, \eta_{\mathrm{p}}^{2}=0.033$.

\section{Attraction}

For attraction to the company, there was a significant main effect of race, $F(1,231)=5.89, p=.016, \eta_{\mathrm{p}}{ }^{2}=0.025$, and message condition, $F(1,231)=5.77, p=.017, \eta_{\mathrm{p}}{ }^{2}=0.024$, with no significant interaction, $F(1,231)=0.81, p=.368$, $\eta_{\mathrm{p}}{ }^{2}=0.005$. Thus, even when controlling for perceptions of racial diversity, participants were more attracted to the organization when they read about a Black woman intern $(M=0.2, S D=0.8)$ relative to a White woman intern $(M=-0.2, S D=1.0)$, and when the past intern conveyed the supportive mentorship message $(M=0.2, S D=0.8)$ relative to no mentorship message $(M=-0.1, S D=1.0)$. Participants reported the highest attraction to the company when they read about a Black woman intern who also indicated the company had supportive out-group mentors and role models; and reported $(M=0.3, S D=0.7)$ significantly higher attraction compared to the three other conditions combined $(M=-0.1, S D=1.0), F(1,233)=5.45, p=.020$, $\eta_{\mathrm{p}}^{2}=0.023$.

\section{Exploratory Analyses}

We next explored whether anticipated identity-safety at the organization acted as a mediator for attraction to the company. For this analysis we focused on the contrast between the Black woman supportive mentorship message condition compared to the other three conditions. Utilizing Hayes (2013) PROCESS macro Model 4 with 5,000 bootstrap resamples, we found a significant indirect effect of this contrast (Black woman supportive message vs. other conditions) on attraction, via anticipated identity-safety, indirect effect $=0.36,95 \%$ CI $[0.14,0.58]$. Participants in the Black woman supportive mentorship message condition reported significantly higher levels of identity-safety than those in the other three conditions, and identity-safety related to higher attraction.

We ran a second exploratory analysis to examine whether relative to the other three conditions, the Black woman supportive mentorship message condition resulted in higher beliefs that role models and mentors can have different identities, which related to identity-safety and, in turn, to higher attraction (i.e., Black woman supportive mentorship message vs. other conditions $\rightarrow$ beliefs about role models and mentors $\rightarrow$ identity-safety $\rightarrow$ attraction). We found a significant indirect effect via this serial mediation pathway, indirect effect $=0.18,95 \%$ CI $[0.08,0.29]$. Compared to the other conditions, participants in the Black woman supportive mentorship message condition believed role models and mentors at Uptown consulting can have different identities, which correlated with higher identity-safety, and identitysafety related to higher attraction.

\section{Discussion}

In this first experiment, we found that in-group organizational endorsement was an effective technique for encouraging identity-safety and organizational attraction, above perceptions of racial diversity. That is, even when controlling for perceptions of racial diversity at the company, Black women participants in the Black woman intern condition indicated stronger beliefs that role models and mentors at Uptown Consulting can have different identities, anticipated more identity-safety at the organization, and reported higher organizational attractiveness and job pursuit intentions for the company, compared to those in the White woman condition. Moreover, relative to those who did not receive this positive message, participants who read about the intern asserting the company had supportive out-group members reported stronger beliefs that role models and mentors at the organization can have different identities, anticipated more identity-safety at the company, and indicated higher attraction to Uptown Consulting. Thus, we found that both components of in-group organizational endorsement had important effects, and having a Black woman endorse a company as having supportive out-group mentors and role models encouraged the highest identity-safety.

\section{Study 2}

Similar to Black women employees, Black women students face unique biases due to their dual marginalized identities (Eaton et al., 2020), and experience higher levels of social identity-threat compared to their male and White women counterparts (Casad et al., 2019; Rainey et al., 2018). Thus, in the current experiment, we were curious whether organizational in-group endorsement would be effective for promoting feelings of identity-safety among Black women students. University environments are particularly relevant for testing the effectiveness of in-group organizational endorsements. Students attend universities for a limited period, and consequently, there are many former alumni who can discuss their experiences at the university. In fact, universities often utilize student testimonials to highlight the positive aspects of the university (Higher Education Marketing, 2016). Moreover, previous research has also employed student testimonials to encourage minoritized students' identity-safety in universities (Walton \& Cohen, 2011; Walton et al., 2015). In this work, older students discussed overcoming difficulties during their first year in a university (e.g., feeling lonely 
during their first year in college; struggling in a course) in order to normalize these challenges and feelings of failure in college (Walton \& Cohen, 2011; Walton et al., 2015). Although employing similar testimonials, in-group organizational endorsement is less focused on normalizing adversity and more focused on highlighting the potential benefits of out-group role models and mentors and endorsing an institution for having a supportive environment.

In Study 2, we explored whether in-group organizational endorsement would improve Black women students' feelings of identity-safety in a university, and whether this enhanced identity-safety would persist over time (i.e., for 6 weeks after viewing the endorsement). Specifically, we recruited Black female students at a large Midwestern university, and either presented them with no video or a video of a successful Black female professor, who was an alumna of the students' university and endorsed the institution. In the pilot study and Study 1, we utilized a fictional article about a fictional company, whereas in the current experiment we employed a video featuring a real alumna, who recounted her actual positive experiences at the university. Consequently, we did not include a White woman control condition, but instead either showed or did not show participants this organizational endorsement video. We opted to utilize a video because previous research has found that videos, relative to written media, can be particularly persuasive (Chaiken \& Eagly, 1983; Pietri et al., 2020). In addition to exploring whether the endorsement video would change general beliefs about the university, we also tested whether this intervention would encourage beliefs that a specific White female professor - not specifically endorsed in the video - valued helping Black women. Finally, we explored whether the endorsement video would encourage professionally beneficial behaviors that can help integrate Black women into the university (i.e., reported professional interactions/ networking during the 6 weeks; Martiny \& Nikitin, 2019).

Although we expected positive outcomes associated with the in-group organizational endorsement video, we anticipated that our results might vary as a function of the rank of the students. Students who are in their last year at the university may not find the information in the video helpful or relevant because they will soon leave the institution and do not need to form new relationships or connections (Petty \& Cacioppo, 1986). These advanced students also may feel discouraged by the message and believe they do not have sufficient time at the university to have similar positive experiences as the alumna (Lockwood \& Kunda, 1997). Because it is possible that the endorsement video may have no influence among students in their $4^{\text {th }}$ year or higher at the university or may even be harmful for these students, we included student year as an exploratory factor in all our analyses for the current experiment.

\section{Method}

\section{Participants}

An a priori power analysis with $\mathrm{G}^{*}$ Power (Faul et al., 2007) indicated that to replicate the findings for differences in identitysafety from Study $1\left(\eta_{\mathrm{p}}{ }^{2}=0.028, f=0.17\right)$ and observe a significant effect at $p<.05$ and $80 \%$ power, we would need a sample of 275 participants. We recruited 338 Black female students who were 18 years or older from a large Midwestern university to take part in the current study, to account for attrition and exclusion due to attention checks and were compensated with \$35 Amazon gift cards. Twenty-two (6.5\%) participants were excluded for failing to answer the attention check question associated the female professor article (this specific attention check question is described below under procedures). These participants did not vary significantly across conditions, $\chi^{2}$ $(1, N=338)=0.83, p=.362$. Participants in the endorsement condition also answered two attention check questions about the video (described below) and an additional 23 (7.2\%) participants were excluded for not correctly answering these questions. This left a sample of 293 participants. From this sample, 79 did not complete Time 2 (i.e., 27.0\% attrition). These 79 participants did not differ significantly across conditions, $\chi^{2}$ $(1, N=293)=0.003, p=.956$. The final sample included 214 Black female students. Students varied across year at the university $\left(40[18.7 \%] 1^{\text {st }}\right.$ year, $50[23.4 \%] 2^{\text {nd }}$ year, $42[19.6 \%] 3^{\text {rd }}$ year, $82[38.3 \%] 4^{\text {th }}$ year or higher), and their age ranged from 18 to $60(M=22.7, S D=6.7)$. Overall, this study employed a time (Time 1 vs. Time 2) by condition (endorsement versus control) design with 101 students assigned to the endorsement video condition and 113 students assigned to the control condition (i.e., no endorsement video).

A power sensitivity analysis using G*Power (Faul et al., 2007) indicated that with a between subjects ANOVA, to observe a significant effect of condition with 1 degree of freedom in the numerator and four groups at $80 \%$ power, we were adequately powered to find a small to medium $(f=0.19)$ effect size at $p<.05$

\section{Procedure}

The current experiment took place during two time points that were 6 weeks apart. Black female students at the university were contacted via email and invited to participate in this experiment. In the email, we described the study as being interested in how women from underrepresented groups react to a short video and/or article, and their feelings about being students at the university generally. If participants agreed to take part in the study, they were redirected to an online survey to complete the first time point. 
At Time 1, we randomly assigned half of the participants to watch the endorsement video (i.e., the endorsement condition) and the other half to view no video (i.e., the control condition). Participants in the endorsement condition were informed they would begin the experiment by watching a short video, and we would then assess their memory and impressions of the video. The endorsement video was similar to the endorsement profiles from Study 1 . However, rather than highlighting a past intern, this video featured a Black female alumna of the students' university who was currently a successful professor in psychology. The video began with the caption "Stories from a Former Student" and the professor briefly described her educational trajectory, which included graduating from the participants' university. The video next presented the caption "How were your experiences at [the students' university]". During this part, the professor noted that she enjoyed attending the university, and described her desire to take part in undergraduate research with a Black female research mentor. Because the professor could not find a mentor matching her identities, she worked in a White women professor's laboratory and had a wonderful experience.

The video next featured the caption "What advice would you give current students at [the students' university]." In this part of the video, the professor advised students that their role models and mentors may not always look like them or have their same identities and mentioned that one of her greatest advocates was her academic advisor, who was a White man. After watching the video, participants in the endorsement condition completed two attention questions to ensure they realized the professor had attended their university (i.e., "The person featured in the video went to what university for her undergraduate degree?") and recognized the professor had positive experiences at the university (i.e., "Was the person in the video involved in undergraduate research?"). Participants in the control condition did not watch a video. Past work has employed similar no video control conditions and found that these conditions yield similar results as video control conditions (see Moss-Racusin et al., 2018; Pietri et al., 2020). Thus, these participants were informed they would read a short article and that we were interested in their impressions and reactions to the article.

Next, participants in both conditions read a short article about a White female professor, Dr. Jane Evans, who ostensibly worked in the computer science department at the students' university and was modelled from previous research (see Pietri et al., 2018b). The article discussed the professor's research and ended with a quote from the professor stating that she appreciates having a diverse research team and believes that diversity improves the quality of research. We included a multiple-choice attention check question to confirm that participants read the article and recognized that the professor valued diversity (i.e., "The person featured in the article said that she: "Values having a diverse research team [correct answer]"). (See Supplement I in the online supplement for the experimental stimuli presented to participants). After reading the article and completing the attention check questions, the participants completed the Time 1 survey. At the end of the survey, participants were informed that they would be contacted in six weeks to complete the second survey, and then compensated with a \$25 Amazon gift card for completing Time 1.

Approximately six weeks later (Time 2), participants received an email invitation to complete the same set of measures as Time 1, and then were redirected to an online survey. At the end of the second session, participants were thanked for their participation, debriefed, and paid a $\$ 10$ Amazon gift card for completing the Time 2 survey.

\section{Measures}

\section{Time 1 Only Measures}

Participants completed a two-item measure assessing their beliefs about whether Dr. Jane Evans cared about helping Black women: "Most likely Dr. Jane Evans cares about issues related to Black women" and "Most likely Dr. Jane Evans wants to help Black women succeed in the sciences"; adapted from Pietri et al., (2018a, b), using a 5-point scale ranging from 1 (strongly disagree) to 5 (strongly agree) $(r=.59, M=3.3, S D=0.7)$. Higher scores indicated more agreement that this White female professor cares about helping Black women.

\section{Time 1 and 2 Measures}

Participants next completed a modified version of the measure for beliefs about role models used in Study 1. (See Supplement $\mathrm{J}$ in the online supplement for the scale items). Beliefs about role models and mentors were significantly correlated at Time 1, $r(212)=0.79, p<.001$, and Time $2, r$ $(212)=0.81, p<.001$. Thus, to be consistent with Study 1 , we averaged the participants' beliefs about role models and beliefs about mentors to create a measure of beliefs that role models and mentors can have different identities at Time 1 and 2. We opted to use non-standardized scores because beliefs about role models and beliefs about mentors had different $\mathrm{z}$-distributions at Time 1 and Time 2, both with means of 0 . Thus, the $\mathrm{z}$-score composite measure would have a mean of 0 at Time 1 and a mean of 0 Time 2 and we would not be able to examine change over time. However, these two measures were on the same rating scale, and hence we could average participants' non-standardized scores to create our composite index for Time 1 (Cronbach's $\alpha=.89$, $M=3.66, S D=0.58$ ) and for Time 2 (Cronbach's $\alpha=.88$, $M=3.51, S D=0.59)$. 
Table 2 Correlations between outcome variables in Study 2

\begin{tabular}{llllllll}
\hline Measure & 1 & 2 & 3 & 4 & 5 & 6 & 7 \\
\hline 1.Perceptions the professor is an ally & - & & & & & & \\
2.Beliefs about role models and mentors (composite) time 1 & $.20^{* * *}$ & & & & & & \\
3.Beliefs about role models and mentors (composite) time 2 & .11 & $.56^{* * *}$ & & & & & \\
4.Identity-Safety (composite) time 1 & $.19^{* * *}$ & $.36^{* * *}$ & $.24^{* * *}$ & & & & \\
5.Identity-Safety (composite) time 2 & $.23^{* *}$ & $.32^{* * *}$ & $.30^{* * *}$ & $.76^{* * *}$ & & & \\
6.Interactions with people who different identities & -.03 & .02 & .06 & .09 & .12 & & \\
7.Interactions with Black women & .05 & -.05 & -10 & .13 & .08 & .01 & - \\
\hline
\end{tabular}

$* * p<.01 . * * * p<.001$

Participants also completed the same measures for trust and comfort used in Study 1. (Supplement G in the online supplement for detailed information on the items comprising the measure of identity-safety). Trust and comfort and belonging also were significantly correlated at Time $1, r(212)=.74, p<.001$, and at Time 2, $r(212)=.73$, $p<.001$. Thus, we averaged the participants' non-standardized scores for trust and comfort and belonging to create our measure of identity-safety at Time 1 (Cronbach's $\alpha=.91$, $M=3.76, S D=0.65$ ) and Time 2 (Cronbach's $\alpha=.91$, $M=3.68, S D=0.64)$.

\section{Time 2 Only Measures}

Participants first reported the number of professional (i.e., networking) interactions that had occurred for them over the past six weeks (since Time 1). We asked participants to reflect on their professional interactions during this time period and report how many interactions they had with people "who could help you as a student and/or in your future career" since completing Time 1. Participants were able to select between 0 to 10 interactions. Based on their responses, participants were next instructed to specify each interaction person with one to two letters/initials. For example, participants who had five interactions indicated the initials of five people. Using these initials, participants then reported the race and gender of each person. We then summed the number of professional interactions that participants had with out-group members (i.e., non-Black women) and with ingroup members (i.e., Black women) during this time period. (See Supplement K in the online supplement for detailed information on the items comprising the measure for experiences of professional interactions).

To ensure participants did not have harmful interactions when connecting with people from different racial and gender groups, we also had participants complete a measure of discriminatory experiences since Time 1 . We did not find that reported discriminatory experiences were impacted by our manipulation and did not correlate with out-group professional interactions. (See Supplement L in the online supplement for detailed information on the items comprising the measure of discriminatory experiences).

\section{Results}

As previously mentioned, we included year at university as an exploratory factor in all subsequent analyses. To examine whether the endorsement video had different effects among students who were close to finishing their college career, we divided students into two groups: $1^{\text {st }}-3^{\text {rd }}$ years (endorsement video: $n=59$; control: $n=73$ ) and $4^{\text {th }}$ years

Table 3 Means and Standard Deviations across Condition and Year in Study 2

\begin{tabular}{|c|c|c|c|c|c|c|c|c|}
\hline \multirow[t]{3}{*}{ Measure } & \multicolumn{4}{|c|}{$1^{\text {st }}-3^{\text {rd }}$ year } & \multicolumn{4}{|c|}{$4^{\text {th }}$ year and above } \\
\hline & \multicolumn{2}{|c|}{ Endorsement video } & \multicolumn{2}{|c|}{ Control } & \multicolumn{2}{|c|}{ Endorsement video } & \multicolumn{2}{|c|}{ Control } \\
\hline & $M$ & $S D$ & $M$ & $S D$ & $M$ & $S D$ & $M$ & $S D$ \\
\hline Perceptions the professor is an ally & 3.52 & 0.74 & 3.23 & 0.77 & 3.04 & 0.70 & 3.28 & 0.78 \\
\hline Beliefs about role models and mentors (composite) time 1 & 3.81 & 0.58 & 3.59 & 0.60 & 3.55 & 0.52 & 3.68 & 0.57 \\
\hline Beliefs about role models and mentors (composite) time 2 & 3.58 & 0.66 & 3.47 & 0.56 & 3.53 & 0.54 & 3.46 & 0.57 \\
\hline Identity-safety (composite) time 1 & 3.94 & 0.64 & 3.68 & 0.68 & 3.65 & 0.70 & 3.78 & 0.54 \\
\hline Identity-safety (composite) time 2 & 3.83 & 0.68 & 3.60 & 0.68 & 3.58 & 0.63 & 3.69 & 0.51 \\
\hline Interactions with people who different identities & 2.66 & 2.04 & 1.77 & 1.69 & 2.31 & 2.24 & 2.95 & 2.05 \\
\hline Interactions with Black women & 0.83 & 1.29 & 0.89 & 1.26 & 0.38 & 0.70 & 0.63 & 0.90 \\
\hline
\end{tabular}


and above (endorsement video: $n=42$; control: $n=40$ ). We present the correlations among the outcome variables in Table 2 and the means and standard deviations across condition and university year in Table 3 .

\section{Beliefs about the professor's values}

We first explored whether participants believed that the White female professor, Dr. Jane Evans, valued the success of Black women. There was no effect of endorsement condition, $F(1,210)=0.04, p=.832, \eta_{\mathrm{p}}{ }^{2}<0.001$. There was, however, a significant effect of year, $F(1,210)=2.43$, $p=.039, \eta_{\mathrm{p}}{ }^{2}=0.020$, which was qualified by a significant condition by year interaction $F(1,210)=6.13, p=.014$, $\eta_{\mathrm{p}}{ }^{2}=0.028$. Among $1^{\text {st }}-3^{\text {rd }}$ year students, those in the endorsement video condition were more likely to believe the professor valued the success of Black women compared to participants in the control condition, mean difference $=0.28, S E=0.13, p=.032, d=0.38$. However, the effect of condition was not significant for $4^{\text {th }}$ year and above students, mean difference $=0.24, S E=0.17$, $p=.150, d=0.32$.

\section{Beliefs that Role Models and Mentors can have Different Identities}

We next tested whether the endorsement video altered beliefs about role models and mentors and whether these effects persisted over time. Specifically, we ran a mixed model ANOVA with condition and year as between-subject variables and time as a within-subject variable. The full ANOVA results are presented in Table 4. There was a significant effect of time: participants' beliefs that role models and mentors can have different identities significantly decreased from Time 1 ( $M=3.7, S D=0.6)$ to Time $2(M=3.5, S D=0.6)$, mean difference $=0.14, S E=0.04 p<.001, d=0.27$. There was also a significant three-way interaction between time, condition, and year $(p=.044)$, indicating that the pattern of results varied across time points. At Time 1, there was a significant two-way interaction between condition and year, $F(1$, $210)=4.60, p=.033, \eta_{\mathrm{p}}{ }^{2}=0.021$. In line with Hypothesis $1 \mathrm{a}$, among $1^{\text {st }}-3^{\text {rd }}$ year students, those in the endorsement condition reported higher beliefs that role models and mentors can have different identities than participants in the control condition, mean difference $=0.22, S E=0.10, p=.031$, $d=0.37$. In contrast, for $4^{\text {th }}$ year and above students, the effect of condition was not significant at Time 1, mean difference $=0.13, S E=0.13, p=.311, d=0.23$. At Time 2, the interaction between condition and year was not significant, $F(1,210)=0.04, p=.839, \eta_{\mathrm{p}}{ }^{2}<0.001$. Although among $1^{\text {st }}-3^{\text {rd }}$ year students the means were in the same direction at Time 2, the effect of condition was no longer significant, mean difference $=0.17, S E=0.17, p=.322, d=0.18$. For

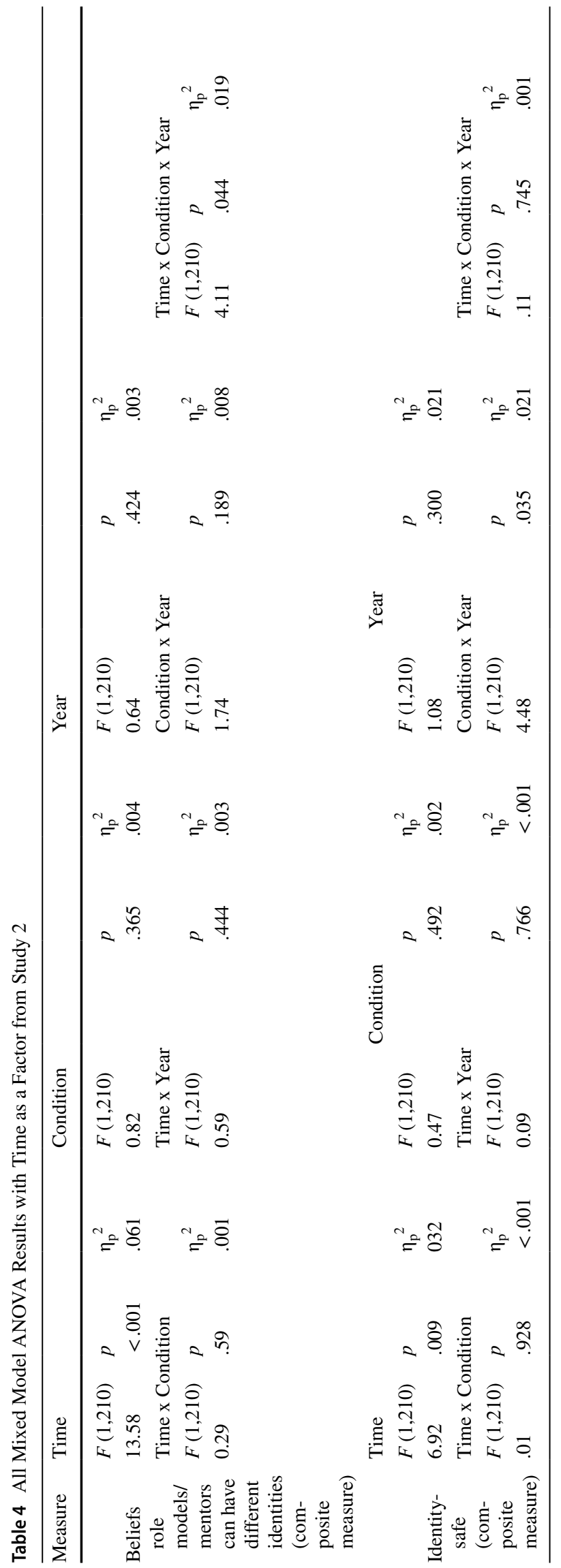


$1^{\text {st }}-3^{\text {rd }}$ year students, the endorsement video initially promoted beliefs that role models and mentors can have different identities; however, this effect did not persist 6 weeks later.

\section{Identity-Safety}

We examined identity-safety across the two time points (see Table 4 for full ANOVA results). We found that participants' identity-safety significantly decreased from Time $1(M=3.8, S D=0.7)$ to Time $2(M=3.7, S D=0.6)$, mean difference $=0.08, S E=0.03, p=.009, d=0.18$. There was also a significant interaction between condition and year $(p=.035)$, but no three-way interaction between year, condition, and time $(p=.745)$, which suggests that the association between condition and year was consistent across the two time points. Supporting Hypothesis 1b, at Time 1 , among $1^{\text {st }}-3^{\text {rd }}$ year students, those in the endorsement condition reported higher identity-safety relative to participants in the control condition, mean difference $=0.25$, $S E=0.11, p=.028, d=0.39$. In contrast, for $4^{\text {th }}$ year and above students, the effect of condition was not significant, mean difference $=0.13, S E=0.14, p=.369, d=0.21$. Showing similar results at Time 2 and consistent with Hypothesis $1 \mathrm{~b}$, among $1^{\text {st }}-3^{\text {rd }}$ year students there was a significant effect of condition, mean difference $=0.23, S E=0.11, p=.046$, $d=0.34$, whereas the effect of condition was not significant for $4^{\text {th }}$ year and above students, mean difference $=0.11$, $S E=0.14, p=.421, d=0.19$. For students in their $1^{\text {st }}-3^{\text {rd }}$ year, the endorsement video encouraged feelings of identitysafety at the university, and this positive effect lasted for 6 weeks after the video.

\section{Professional Interactions}

We examined whether enhancing participants' identitysafety at the university would promote more professional interactions/networking. Because number of interactions was a count variable with a non-normal distribution, we employed a Poisson regression (Coxe et al., 2009), with condition dummy coded ( $1=$ Intervention, $0=$ Control), year dummy coded $\left(1=1^{\text {st }}-3^{\text {rd }}\right.$ years, $0=4^{\text {th }}$ year and above), and the interaction between these two variables. We ran this model predicting number of interactions with outgroup members (i.e., non-Black women) and with in-group members (i.e., Black women). The initial models showed a significant overdispersion (i.e., the model had greater variability than expected for a standard Poisson regression, or $\varphi=\chi_{\text {Pearson }}^{2} / D F$ that was greater than 1 [all $>1.51$ ]; Coxe, et al., 2009), and as a result, we ran an over dispersed Poisson model employing a scaling parameter (Coxe et al., 2009; Land et al., 1996).
Looking at professional interactions with out-group members, there was a significant year by condition interaction, $b=0.65$, Wald's $\chi^{2}(1, N=214)=7.28, p=.007$. Probing this interaction, we found that among $1^{\text {st }}-3^{\text {rd }}$ year students, those in the endorsement condition were more likely to have professional interactions with out-group members than participants in the control condition, $b=0.41$ Wald's $\chi^{2}(1, N=214)=6.65, p=.010$, which supported Hypothesis $1 \mathrm{~b}$. In contrast, for $4^{\text {th }}$ year and above students, the effect of condition was not significant $b=-0.25$ Wald's $\chi^{2}(1, N=214)=1.79, p=.181$. Predicting interactions with in-group members (i.e., Black women), we did not see a significant interaction between year and condition, $b=0.43$ Wald's $\chi^{2}(1, N=214)=0.87, p=.352$, and thus, we ran this model without the interaction term. We found that on average, $1^{\text {st }}-3^{\text {rd }}$ year students were more likely to have interactions with Black women than $4^{\text {th }}$ year and above students, $b=0.54$, Wald's $\chi^{2}(1, N=214)=5.69, p=.017$, and the effect of condition was not significant, $b=-0.18$, Wald's $\chi^{2}(1, N=214)=0.83, p=.362$. Thus, organizational endorsement was most effective at encouraging interactions with individuals from out-groups among $1^{\text {st }}-3^{\text {rd }}$ year students.

\section{Exploratory Mediation Analyses}

Similar to Study 1, we also explored whether identity-safety at Time 1 acted as a significant mediator linking the effect of condition to interactions with out-group members at Time 2 . Because the effect of condition on identity-safety and outgroup members interactions was only significant for $1^{\text {st }}-3^{\text {rd }}$ year students, we focused our analysis on these students. Of importance, among these $1^{\text {st }}-3^{\text {rd }}$ year students, identity-safety at Time 1 predicted interactions with out-group members at Time 2, $b=0.18$, Wald's $\chi^{2}(1, N=132)=4.22$, $p=.040$.

To test for a significant indirect effect, we used the mediation software in $R$ because it can calculate count variable outcomes (Tingley et al., 2019). This approach creates confidence intervals using a quasi-Bayesian Monte Carlo approximation and 1,000 simulations (see Imai et al., 2010 for discussion of approach). For $1^{\text {st }}-3^{\text {rd }}$ year students, we found a significant mediation effect of condition on interactions with out-group members via identity-safety at Time 1 (effect $=0.12,95 \%$ CIs $[0.01,0.03]$ ).

\section{Exploratory Moderation Analyses}

We ran additional regression analyses treating year as a continuous variable rather than a dichotomous variable to further explore who benefits from in-group organizational endorsement. The interactions between year (treated as a 


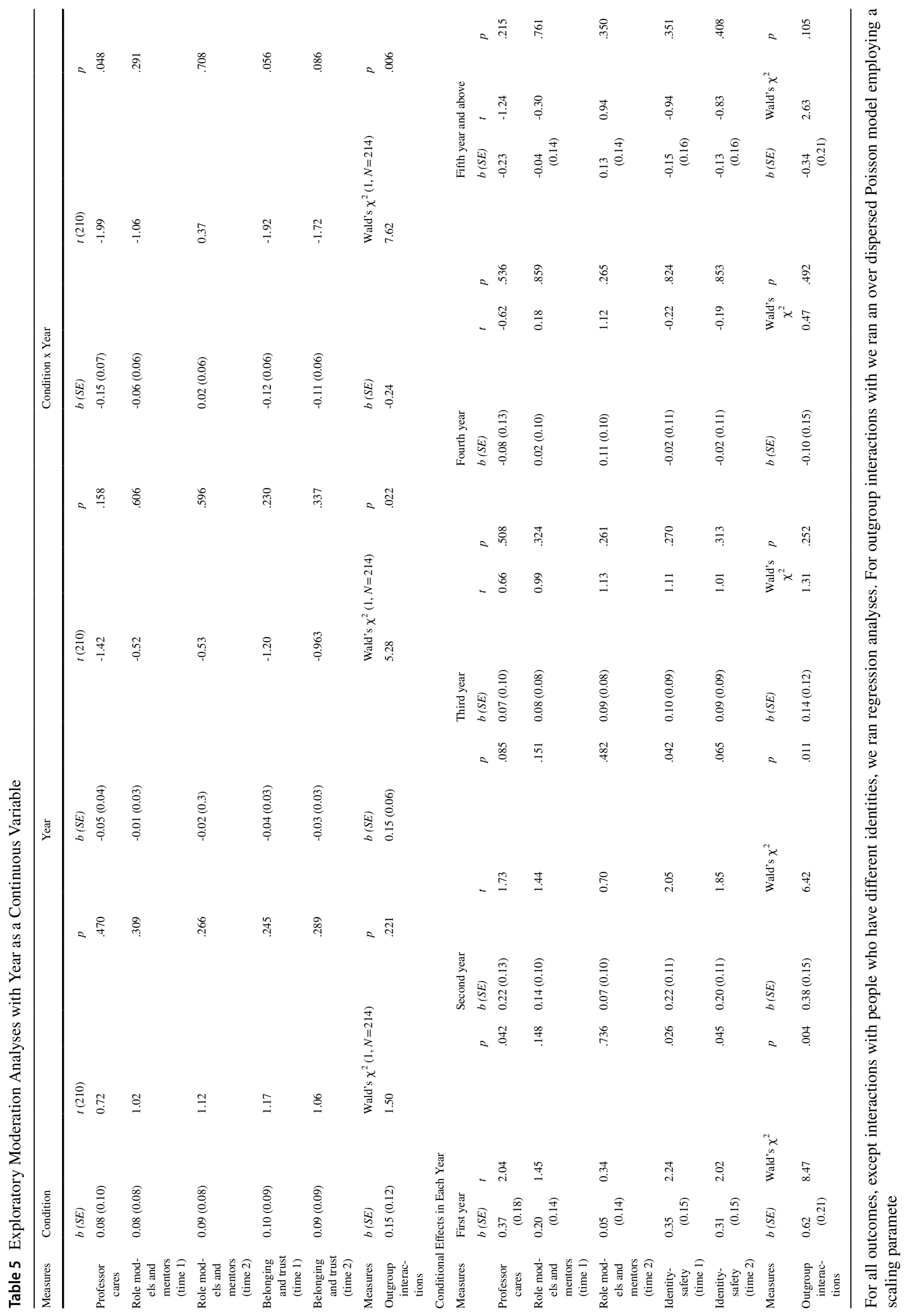


continuous variable) and condition and the conditional effects of condition in each year (i.e., $1^{\text {st }}$ years $-4^{\text {th }}$ year and above) are presented in Table 5. We observed the general pattern that in-group organizational endorsement was most beneficial for students in their $1^{\text {st }}$ year. That is, there was a significant effect of condition for $1^{\text {st }}$ year students on perceptions that the professor cares about Black women $(p=.042)$, identity-safety at Time $1(p=.026)$ and at Time $2(p=.045)$, and professional interactions with people who have different identities $(p=.004)$. There was also a significant effect of condition for $2^{\text {nd }}$ year students on identity-safety at Time $2(p=.042)$ and professional interactions with people who have different identities $(p=.011)$. Although the effects were in the expected direction, no effects were significant for $3^{\text {rd }}$ year students or above.

\section{Discussion}

In Study 2, we demonstrated that in-group organizational endorsement had positive effects for Black female students early in their career at a large university. Relative to those who did not watch an endorsement video, immediately after watching the endorsement video, students in the $1^{\text {st }}-3^{\text {rd }}$ year were more likely to report that the White female professor portrayed in the video values the success of Black women, role models and mentors can have different identities, and more feelings of identity-safety at their university. At the 6-week follow-up, compared to those in the control condition, Black female students in their $1^{\text {st }}-3^{\text {rd }}$ year who viewed the endorsement video indicated higher identity-safety and reported more professional interactions with individuals who have different identities (i.e., were not Black women).

There was no effect of endorsement video among Black female students in their $4^{\text {th }}$ year or above at the university. Moreover, exploratory moderation analyses found that ingroup organizational endorsement was most beneficial for students in their 1st year at university. Students who are early in their college career may perceive that they have time at university to have similar positive experiences as the alumna in the video (Lockwood \& Kunda, 1997). In contrast, students who are farther along in their college careers may have found the message to be irrelevant because they have little time remaining at the university (Lockwood \& Kunda, 1997) or because the message does not match their previous experiences at the university (Wilton et al., 2020). Thus, in-group organizational endorsement may be most beneficial for individuals who are just beginning at a school or company.

\section{General Discussion}

The current studies examined whether a new organizational diversity strategy, in-group organizational endorsement, functioned as an effective cue to encourage identity-safety among Black women. Across one pilot experiment and two primary experiments, we found that in-group organizational endorsement can be an efficacious intervention. Specifically, Study 1 tested each component of in-group organizational endorsement separately and demonstrated the importance of both elements (i.e., presence of an in-group member and organizational endorsement). That is, learning that a Black woman (i.e., a racial in-group member) was successful in an organization was more beneficial than learning about the success of a White woman. Moreover, a message asserting that an organization has supportive out-group role models and mentors (from a Black woman or White woman as the source) resulted in more positive outcomes than no message. Thus, we found that a Black woman endorsing a company as having supportive out-group mentors and role models promoted the highest identity-safety and differed significantly from the other three conditions combined.

In Study 2, we found that among Black female students in their $1^{\text {st }}-3^{\text {rd }}$ year at university, those who watched a video of a Black female alumna endorsing the school reported higher beliefs that role models and mentors can have different identities, stronger beliefs that a specific White female professor cared about supporting Black women, and more identitysafety at the university, relative to students who did not watch the video. Moreover, the positive effects of endorsement on identity-safety persisted for six weeks after viewing the video. We also found that the in-group organizational endorsement video led to self-reported behavior change. For students in their $1^{\text {st }}-3^{\text {rd }}$ year, those in the endorsement video condition reported having more professional interactions with people of different identities relative to students in the control condition. However, this in-group organizational endorsement was not effective for students in their $4^{\text {th }}$ year or higher. Exploratory analyses also found that $1^{\text {st }}$ year students benefited the most from the endorsement video, suggesting that in-group endorsement is most beneficial for prospective or new employees/students.

These findings suggest a new effective strategy to encourage identity-safety within organizations that lack racial diversity but are striving to address this disparity through the implementation of multiple policies and trainings (Onyeador et al., 2021). Specifically, prior to signaling that their institution cares about supporting Black women, organizations must first foster a culture appreciative of diversity and ensure the equitable treatment of employees (Avery \& McKay, 2010; McKay et al., 2008). Creating a pro-diversity climate will encourage employees to be respectful and value diversity within their working groups (Homan et al., 2007; 2010; Nishii, 2013) and will help attract other employees who value inclusion and dismantling the status quo (Onyeador et al., 2021). As organizations work to create welcoming climates, they may want 
to demonstrate their pro-diversity values as well as their supportive employees. Rather than having the organization deliver a broad diversity statement, we found that having a previous employee endorse the organization as inclusive, acted as an effective identity-safe cue. Thus, the current studies add to research on diversity management strategies and particularly organizational diversity statements.

The current research also demonstrated the importance of considering the identities of the source of the diversity statement communication, particularly for Black women. In Study 1, Black women were more likely to believe the organizational endorsement message when it came from a racial ingroup member (i.e., a Black woman) than when it came from a racial out-group member (i.e., a White woman). The current research therefore adds to the growing body of research demonstrating that a singular focus on gender-relevant cues may not be as effective for Black women's identity-safety in the absence of race-relevant cues (Johnson et al., 2019; Pietri et al., 2018a; Remedios \& Snyder, 2015). Moreover, the current work highlights the importance of considering individuals' multiple identities when studying in-group persuasion effects (Esposo et al., 2013; Mackie et al., 1990, 1992). Our findings suggest that there might be variability in the strength of in-group persuasion depending on whether a source matches only one or multiple identities. In Study 1, we found that communication by a White woman that the organization has supportive out-group role models and mentors was more beneficial than simply learning that a White woman had a successful experience as an intern at the company. Thus, among Black women, a message from a source matching only their gender can still be persuasive but remains less effective at fostering identity-safety than a message delivered by a source who matches their gender and race.

\section{Limitations and Future Research}

A limitation of the current research is that we did not explore whether a diversity statement is more effective when it comes from a former versus current employee. An organization leader may be motivated to promote a positive image of their company, which may discredit their trustworthiness (Eagly et al., 1978; Walster et al., 1966; Wilton et al., 2020; Windscheid et al., 2016). Moreover, although current employees can be seen as credible sources of information (Fisher et al., 1979; Van Hoye \& Lievens, 2007; Walker et al., 2009), job seekers may question the trustworthiness of testimonials from these employees (Highhouse et al., 2002). In contrast, former employees do not benefit from endorsing their past job, which may enhance their believability. Thus, it will be important to explore in future work the unique benefits of an organizational endorsement from a former (versus a current) employee or student.
Relatedly, future research might also continue to explore the importance of the race versus gender of the source who is endorsing the organization or university. In the current studies, we held gender constant and only manipulated the race of the former employee. However, among Black women, an organizational endorsement message from a former Black male employee or student may be more effective than a message from a White woman and equally effective as a message from a Black woman (see Johnson et al., 2019; Pietri et al., 2018a). Finally, future research might also explore whether this message is effective without a specific source. That is, would having Black women read a general message suggesting that role models and mentors can have different identities increase their trust of out-group members across different settings? Although this is a theoretically interesting question, we do caution that a broad message (not associated with a specific inclusive organization) could result in Black women approaching potentially unsupportive out-group members.

Future research also should explore the psychological consequences of asking a former employee or student to give an organizational endorsement. It is possible that when former employees or students had a positive experience, they would feel comfortable communicating this information to others. However, it will be important to ensure that previous employees or students do not feel targeted or tokenized when asked to provide an endorsement (see Abebe \& Dadanlar, 2021). Critically, when former employees or students did not have a positive experience, they should not feel any obligation to provide the endorsement because they are no longer affiliated with that organization. In addition, future research should also test whether in-group organizational endorsement is achieved by noting that an organization has supportive role models and mentors. It may be that simply stating an organization has supportive role models and mentors would be beneficial and could by itself promote identity-safety. However, it might also convey that an organization has gender and racial diversity, which could be misleading if the organization lacks diversity.

Finally, in future research, it will be critical to continue exploring the effects of in-group organizational endorsement among Black women who are established in organizations. The findings from Study 2 suggest that this strategy may be most effective for attracting Black women to a company, or as part of the onboarding process for new employees/students. When Black women have been in an organization for a while, they may struggle to believe the message when it does not align with their own experiences (Wilton et al., 2020). Future studies also might test the effects of in-group organizational endorsement for Black women at higher levels in their career, such as leadership positions, who face additional mistreatment and biases because of their high-status positions (Rosette \& Livingston, 2012; Rosette et al., 2016). 


\section{Practice Implications}

Companies and universities often display diversity statements on their websites or brochures without a specific source or with an organizational leader delivering the message (Avery, et al., 2013; Purdie-Vaughns et al., 2008). When there are additional conflicting cues in the company (i.e., a lack of racial diversity; Wilton et al., 2020; Windscheid et al., 2016), employees may not trust the diversity statement or organization. We offer a practical alternative to diversity statements by demonstrating the effectiveness of using past employees from the in-group advocating and endorsing the organization as a place where they can thrive and feel safe in their identities. Moreover, this strategy may more accurately reflect an organization's inclusivity practices than a diversity message. Although organizations and employees may indicate they value diversity for superficial reasons, others may be intrinsically motivated to recruit and promote Black women in their organizations (Plant \& Devine, 1998, 2001). Black women may not trust, and therefore, not endorse organizations who are disingenuous in their diversity efforts (Dovidio et al., 2002; Wilton et al., 2020; Windscheid et al., 2016).

We therefore recommend in-group organizational endorsement as a strategy for institutions that are actively working to promote inclusivity and address any unfair treatment in their organization. That is, prior to employing this strategy, companies and universities should have implemented multiple changes to encourage welcoming environments. Indeed, this technique is not feasible when companies or universities lack an inclusive organizational culture and employees who intrinsically care about diversity (i.e., no past employee or student would endorse the company or university). Moreover, previous research has found that using testimonials to encourage identity-safety is an ineffective strategy when an environment does not afford belonging or is unwelcoming (Walton \& Yeager, 2020).

Although outgroup mentors can be beneficial (BlakeBeard et al., 2011; Downing et al., 2005), ideally students and employees would also have opportunities to interact with mentors and role models matching their most important identities. Thus, the goal of in-group organizational endorsement is to enhance an institution's diversity. Related to this goal, we found that in-group organizational endorsement encouraged Black women to approach professional opportunities, including job pursuit intentions for a company. Increasing the representation of Black women would not only increase diversity within the organization, but also has the potential to continue attracting Black women to that institution. That is, successful Black women employees can act as identity-safe cues to encourage other Black women to enter and thrive within a company (Johnson et al., 2019; Pietri et al., 2018a).

\section{Conclusion}

Overall, our findings highlight the importance and utility of in-group organizational endorsement as an effective identity-safe cue among Black women. Specifically, this strategy increases identity-safety and beliefs that role models and mentors can have different identities, both of which are crucial for Black women to not only feel comfortable but flourish within an organizational setting. Continuing to understand the precursors of identity-safety in institutions will have important implications for diversifying companies and universities. Thus, as institutions work to create welcoming and inclusive environments through multiple policies and trainings, in-group organizational endorsement is an additional and beneficial technique that organizations can implement to attract and retain diverse talent.

\section{Funding Source}

This research was supported by a Small Grant from the Spencer Foundation which was awarded to the second and third author of this paper.

Supplementary Information The online version contains supplementary material available at https://doi.org/10.1007/s11199-021-01253-2.

\section{Compliance with Ethical Standards}

Research Involving Human Participants This research did involve human participants, which we received IRB approval to conduct. Please see attached for IRB exemption documentation.

Disclosure of Potential Conflicts of Interest The authors have no conflicts of interest to declare that are relevant to the content of this article.

\section{References}

Abebe, M., \& Dadanlar, H. (2021). From tokens to key players: The influence of board gender and ethnic diversity on corporate discrimination lawsuits. Human Relations, 74(4), 527-555. https:// doi.org/10.1177/0018726719888801

Abrams, D., \& Hogg, M. A. (Eds.). (1999). Social identity and social cognition (pp. 196-229). Wiley-Blackwell. https://www.wiley.com/ en-ar/Social+Identity+and+Social+Cognition-p-9780631206439

Allen, T. D., Eby, L. T., Poteet, M. L., Lentz, E., \& Lima, L. (2004). Career benefits associated with mentoring for proteges: A meta-analysis. Journal of Applied Psychology, 89(1), 127-136. https://doi.org/10.1037/0021-9010.89.1.127

Allen, V. L. (1975). Social support for nonconformity. In Advances in experimental social psychology (Vol. 8, pp. 1-43). Academic Press. https://doi.org/10.1016/S0065-2601(08)60247-6

Asgari, S., Dasgupta, N., \& Stout, J. G. (2011). When do counterstereotypic ingroup members inspire versus deflate? The effect of successful professional women on young women's leadership self-concept. Personality and Social Psychology Bulletin, 38(3), 370-383. https://doi.org/10.1177/0146167211431968 
Avery, D. R., Hernandez, M., \& Hebl, M. R. (2004). Who's watching the race? Racial salience in recruitment advertising. Journal of Applied Social Psychology, 34(1), 146-161. https://doi.org/ 10.1111/j.1559-1816.2004.tb02541.x

Avery, D. R., \& McKay, P. F. (2010). Doing diversity right: An empirical based approach to effective diversity management. In G. P. Hodgkinson \& J. K. Ford (Eds.), International Review of Industrial and Organizational Psychology (pp. 227-252). John Wiley \& Sons. https://doi.org/10.1002/9780470661628.ch6

Avery, D. R., Volpone, S. D., Stewart, R. W., Luksyte, A., Hernandez, M., McKay, P. F., \& Hebl, M. R. (2013). Examining the draw of diversity: How diversity climate perceptions affect job-pursuit intentions. Human Resource Management, 52(2), 175-193. https:// doi.org/10.1002/hrm.21524

Banchefsky, S., Lewis, K. L., \& Ito, T. A. (2019). The role of social and ability belonging in men's and women's PSTEM persistence. Frontiers in Psychology, 10, Article 2386. https://doi.org/ 10.3389/fpsyg. 2019.02386

Berdahl, J. L., \& Moore, C. (2006). Workplace harassment: Double jeopardy for minority women. Journal of Applied Psychology, 91(2), 426-436. https://doi.org/10.1037/0021-9010.91.2.426

Bezrukova, K., Spell, C. S., Perry, J. L., \& Jehn, K. A. (2016). A metaanalytical integration of over 40 years of research on diversity training evaluation. Psychological Bulletin, 142(11), 1227-1274. https://doi.org/10.1037/bul0000067

Blake-Beard, S., Bayne, M. L., Crosby, F. J., \& Muller, C. B. (2011). Matching by race and gender in mentoring relationships: Keeping our eyes on the prize. Journal of Social Issues, 67(3), 622643. https://doi.org/10.1111/j.1540-4560.2011.01717.x

Buunk, A. P., Peiró, J. M., \& Griffioen, C. (2007). A positive role model may stimulate career-oriented behavior. Journal of Applied Social Psychology, 37(7), 1489-1500. https://doi.org/ 10.1111/j.1559-1816.2007.00223.x

Casad, B. J., Petzel, Z. W., \& Ingalls, E. A. (2019). A model of threatening academic environments predicts women STEM majors' self-esteem and engagement in STEM. Sex Roles, 80(7), 469-488. https://doi.org/10.1007/s11199-018-0942-4

Chaiken, S., \& Eagly, A. H. (1983). Communication modality as a determinant of persuasion: The role of communicator salience. Journal of Personality and Social Psychology, 45(2), 241-256. https://doi.org/10.1037/0022-3514.45.2.241

Chen, A. (2017). Addressing diversity on college campuses: Changing expectations and practices in instructional leadership. Higher Education Studies, 7(2), 17-22. https://doi.org/10. 5539/hes.v7n2p17

Clark, R. D., \& Maass, A. (1988a). Social categorization in minority influence: The case of homosexuality. European Journal of Social Psychology, 18(4), 347-364. https://doi.org/10.1002/ejsp. 2420180405

Clark, R. D., \& Maass, A. (1988b). The role of social categorization and perceived source credibility in minority influence. European Journal of Social Psychology, 18(5), 381-394. https://doi.org/10. 1002/ejsp.2420180502

Cole, E. R. (2008). Coalitions as a model for intersectionality: From practice to theory. Sex Roles, 59(5-6), 443-453. https://doi.org/ 10.1007/s11199-008-9419-1

Cole, E. R. (2009). Intersectionality and research in psychology. American Psychologist, 64(3), 170-180. https://psycnet.apa.org/doi/ 10.1037/a0014564

Coles, S. M., \& Pasek, J. (2020). Intersectional invisibility revisited: How group prototypes lead to the erasure and exclusion of Black women. Translational Issues in Psychological Science, 6(4), 314-324. https://doi.org/10.1037/tps0000256

Cook, A., \& Glass, C. (2014). Women and top leadership positions: Towards an institutional analysis. Gender, Work \& Organization, 21(1), 91-103. https://doi.org/10.1111/gwao.12018
Cortina, L. M., Kabat-Farr, D., Leskinen, E. A., Huerta, M., \& Magley, V. J. (2013). Selective incivility as modern discrimination in organizations: Evidence and impact. Journal of Management, 39(6), 1579-1605. https://doi.org/10.1177/0149206311418835

Coxe, S., West, S. G., \& Aiken, L. S. (2009). The analysis of count data: A gentle introduction to poisson regression and its alternatives. Journal of Personality Assessment, 91(2), 121-136. https://doi.org/10.1080/00223890802634175

Crenshaw, K. (1991). Race, gender, and sexual harassment. s. Cal. l. Rev., 65, 1467.

Dasgupta, N. (2011). Ingroup experts and peers as social vaccines who inoculate the self-concept: The stereotype inoculation model. Psychological Inquiry, 22(4), 231-246. https://doi.org/10.1080/ 1047840X.2011.607313

Davies, P. G., Spencer, S. J., \& Steele, C. M. (2005). Clearing the air: Identity safety moderates the effects of stereotype threat on women's leadership aspirations. Journal of Personality and Social Psychology, 88(2), 276-287. https://doi.org/10.1037/ 0022-3514.88.2.276

Dennehy, T. C., \& Dasgupta, N. (2017). Female peer mentors early in college increase women's positive academic experiences and retention in engineering. Proceedings of the National Academy of Sciences, 114(23), 5964-5969. https://doi.org/10.1073/pnas. 1613117114

Dovidio, J. F., Gaertner, S. E., Kawakami, K., \& Hodson, G. (2002). Why can't we just get along? Interpersonal biases and interracial distrust. Cultural Diversity and Ethnic Minority Psychology, 8(2), 88-102. https://doi.org/10.1037/1099-9809.8.2.88

Downey, S. N., van der Werff, L., Thomas, K. M., \& Plaut, V. C. (2014). The role of diversity practices and inclusion in promoting trust and employee engagement. Journal of Applied Social Psychology, 45(1), 35-44. https://doi.org/10.1111/jasp.12273

Downing, R. A., Crosby, F. J., \& Blake-Beard, S. (2005). The perceived importance of developmental relationships on women undergraduates' pursuit of science. Psychology of Women Quarterly, 29(4), 419-426. https://doi.org/10.1111/j.1471-6402.2005.00242.x

Eagly, A. H., Wood, W., \& Chaiken, S. (1978). Causal inferences about communicators and their effect on opinion change. Journal of Personality and Social Psychology, 36(4), 424-435. https://doi. org/10.1037/0022-3514.36.4.424

Eaton, A. A., Saunders, J. F., Jacobson, R. K., \& West, K. (2020). How gender and race stereotypes impact the advancement of scholars in STEM: Professors' biased evaluations of physics and biology postdoctoral candidates. Sex Roles, 82(5), 127-141. https://doi. org/10.1007/s11199-019-01052-w

Eby, L. T., Allen, T. D., Evans, S. C., Ng, T., \& DuBois, D. L. (2008). Does mentoring matter? A multidisciplinary meta-analysis comparing mentored and non-mentored individuals. Journal of Vocational Behavior, 72(2), 254-267. https://doi.org/10.1016/j. jvb.2007.04.005

Esposo, S. R., Hornsey, M. J., \& Spoor, J. R. (2013). Shooting the messenger: Outsiders critical of your group are rejected regardless of argument quality. British Journal of Social Psychology, 52(2), 386-395. https://doi.org/10.1111/bjso.12024

Faul, F., Erdfelder, E., Lang, A. G., \& Buchner, A. (2007). G* Power 3: A flexible statistical power analysis program for the social, behavioral, and biomedical sciences. Behavior Research Methods, 39(2), 175-191. https://doi.org/10.3758/bf03193146

Fisher, C. D., Ilgen, D. R., \& Hoyer, W. D. (1979). Source credibility, information favorability, and job offer acceptance. Academy of Management Journal, 22(1), 94-103. https://doi.org/10.5465/255481

Fowler, J. L., Gudmundsson, A. J., \& O'Gorman, J. G. (2007). The relationship between mentee-mentor gender combination and the provision of distinct mentoring functions. Women in Management Review, 22(8), 666-681. https://doi.org/10.1108/ 09649420710836335 
Galinsky, A. D., Hall, E. V., \& Cuddy, A. J. (2013). Gendered races: Implications for interracial marriage, leadership selection, and athletic participation. Psychological Science, 24(4), 498-506.

Gibson, D. E. (2004). Role models in career development: New directions for theory and research. Journal of Vocational Behavior, 65(1), 134-156. https://doi.org/10.1016/S0001-8791(03)00051-4

Good, C., Rattan, A., \& Dweck, C. S. (2012). Why do women opt out? Sense of belonging and women's representation in mathematics. Journal of Personality and Social Psychology, 102(4), 700. https://doi.org/10.1037/a0026659

Hall, W. M., Schmader, T., \& Croft, E. (2015). Engineering exchanges: Daily social identity threat predicts burnout among female engineers. Social Psychological and Personality Science, 6(5), 528534. https://doi.org/10.1177/1948550615572637

Hancock, A. (2007). When multiplication doesn't equal quick addition: Examining intersectionality as a research paradigm. Perspectives on Politics, 5(1), 63-79. https://doi.org/10.1017/ S1537592707070065

Hayes, A. F. (2013). Introduction to mediation, moderation, and conditional process analysis: A regression-based approach. Journal of Educational Measurement, 51(3), 335-337. https://doi.org/ 10.1111/jedm. 12050

Higher Education Marketing. (2016). 8 ways to recycle student testimonials for maximum recruitment mileage. https://www.highereducation-marketing.com/blog/maximize-testimonials

Highhouse, S., Hoffman, J. R., Greve, E. M., \& Collins, A. E. (2002). Persuasive impact of organizational value statements in a recruitment context. Journal of Applied Social Psychology, 32(8), 1737-1755. https://doi.org/10.1111/j.1559-1816.2002. tb02773.x

Highhouse, S., Lievens, F., \& Sinar, E. F. (2003). Measuring attraction to organizations. Educational and Psychological Measurement, 63(6), 986-1001. https://doi.org/10.1177/ 0013164403258403

Holleran, S. E., Whitehead, J., Schmader, T., \& Mehl, M. R. (2011). Talking shop and shooting the breeze: A study of workplace conversation and job disengagement Among STEM Faculty. Social Psychological and Personality Science, 2(1), 65-71. https://doi. org/10.1177/1948550610379921

Homan, A. C., Greer, L. L., Jehn, K. A., \& Koning, L. (2010). Believing shapes seeing: The impact of diversity beliefs on the construal of group composition. Group Processes \& Intergroup Relations, 13(4), 477-493.

Homan, A. C., Van Knippenberg, D., Van Kleef, G. A., \& De Dreu, C. K. (2007). Bridging faultlines by valuing diversity: diversity beliefs, information elaboration, and performance in diverse work groups. Journal of applied psychology, 92(5), 1189.

Imai, K., Keele, L., \& Tingley, D. (2010). A general approach to causal mediation analysis. Psychological Methods, 15(4), 309334. https://doi.org/10.1037/a0020761

Insko, C. A., Smith, R. H., Alicke, M. D., Wade, J., \& Taylor, S. (1985). Conformity and group size: The concern with being right and the concern with being liked. Personality and Social Psychology Bulletin, 11(1), 41-50. https://doi.org/10.1177/0146167285111004

Jayne, M. E. A., \& Dipboye, R. L. (2004). Leveraging diversity to improve business performance: Research findings and recommendations for organizations. Human Resource Management, 43(4), 409-424. https://doi.org/10.1002/hrm.20033 https://doi. org $/ 10.1002 / \mathrm{hrm} .20033$

Johnson, I. R., \& Pietri, E. S. (2020). An ally you say? Endorsing White women as allies to encourage perceptions of allyship and organizational identity-safety among Black women. Group Processes \& Intergroup Relations. https://doi.org/10.1177/ 1368430220975482

Johnson, I. R., Pietri, E. S., Fullilove, F., \& Mowrer, S. (2019). Exploring identity-safety cues and allyship among Black women students in STEM environments. Psychology of Women Quarterly, 43(2), 131-150. https://doi.org/10.1177/0361684319830926

van Knippenberg, D., Lossie, N., \& Wilke, H. (1994). In-group prototypicality and persuasion: Determinants of heuristic and systematic message processing. British Journal of Social Psychology, 33(3), 289-300. https://doi.org/10.1111/j.2044-8309.1994. tb01026.x

Land, K. C., McCall, P. L., \& Nagin, D. S. (1996). A comparison of Poisson, negative binomial, and semiparametric mixed Poisson regression models: With empirical applications to criminal careers data. Sociological Methods \& Research, 24(4), 387-442. https://doi.org/10.1177/0049124196024004001

Li, Y., Perera, S., Kulik, C. T., \& Metz, I. (2019). Inclusion climate: A multilevel investigation of its antecedents and consequences. Human Resource Management, 58(4), 353-369. https://doi.org/ 10.1002/hrm.21956

Livingston, R. W., Rosette, A. S., \& Washington, E. F. (2012). Can an Agentic Black Woman Get Ahead? The Impact of Race and Interpersonal Dominance on Perceptions of Female Leaders. Psychological Science, 23(4), 354-358. https://doi.org/10.1177/ 0956797611428079

Lockwood, P., \& Kunda, Z. (1997). Superstars and me: Predicting the impact of role models on the self. Journal of Personality and Social Psychology, 73(1), 91-103. https://doi.org/10.1037/00223514.73.1.91

MacKie, D. M., Gastardo-Conaco, M. C., \& Skelly, J. J. (1992). Knowledge of the Advocated Position and the Processing of In-Group and Out-Group Persuasive Messages. Personality and Social Psychology Bulletin, 18(2), 145-151. https://doi.org/10.1177/ 0146167292182005

Mackie, D. M., Worth, L. T., \& Asuncion, A. G. (1990). Processing of persuasive in-group messages. Journal of Personality and Social Psychology, 58(5), 812-822. https://doi.org/10.1037/0022-3514. 58.5.812

Martiny, S. E., \& Nikitin, J. (2019). Social identity threat in interpersonal relationships: Activating negative stereotypes decreases social approach motivation. Journal of Experimental Psychology: Applied, 25(1), 117-128. https://doi.org/10.1037/xap0000198

McKay, P. F., Avery, D. R., \& Morris, M. A. (2008). Mean racialethnic differences in employee sales performance: The moderating role of diversity climate. Personnel psychology, 61(2), 349-374.https://doi.org/10.1111/j.1744-6570.2008.00116.x

Misra, J., Smith-Doerr, L., Dasgupta, N., Weaver, G., \& Normanly, J. (2017). Collaboration and Gender Equity among Academic Scientists. Social Sciences, 6(1), 25. https://doi.org/10.3390/ socsci6010025

Morgenroth, T., Ryan, M. K., \& Peters, K. (2015). The motivational theory of role modeling: How role models influence role aspirants' goals. Review of General Psychology, 19(4), 465-483. https://doi.org/10.1037/gpr0000059

Moss, A., \& Litman, L. (2018). After the bot scare: Understanding what's been happening with data collection on MTurk and how to stop it. Retrieved February, 4, 2019.

Moss-Racusin, C. A., Pietri, E. S., Hennes, E. P., Dovidio, J. F., Brescoll, V. L., Roussos, G., \& Handelsman, J. (2018). Reducing STEM gender bias with VIDS (video interventions for diversity in STEM). Journal of Experimental Psychology: Applied, 24, 236-260. https://doi.org/10.1037/xap0000144

Moss-Racusin, C. A., Pietri, E. S., van der Toorn, J., \& Ashburn-Nardo, L. (2021). Boosting the Sustainable Representation of Women in STEM With Evidence-Based Policy Initiatives. Policy Insights from the Behavioral and Brain Sciences, 8(1), 50-58. https://doi. org/10.1177/2372732220980092

Moss-Racusin, C. A., van der Toorn, J., Dovidio, J. F., Brescoll, V. L., Graham, M. J., \& Handelsman, J. (2016). A "scientific diversity" intervention to reduce gender bias in a sample of life scientists. 
CBE-Life Sciences Education, 15(3), ar29. https://doi.org/10. 1187/cbe.15-09-0187

Murphy, M. C., Steele, C. M., \& Gross, J. J. (2007). Signaling Threat: How Situational Cues Affect Women in Math, Science, and Engineering Settings. Psychological Science, 18(10), 879-885. https://doi.org/10.1111/j.1467-9280.2007.01995.x

Murphy, M. C., \& Taylor, V. J. (2012). The role of situational cues in signaling and maintaining stereotype threat. In M. Inzlicht \& T. Schmader (Eds.), Stereotype threat: Theory, process, and application (pp. 17-33). Oxford University Press.

Nishii, L. H. (2013). The benefits of climate for inclusion for genderdiverse groups. Academy of Management Journal, 56(6), 17541774. https://doi.org/10.5465/amj.2009.0823

Noe, R. A. (1988). An Investigation of the Determinants of Successful Assigned Mentoring Relationships. Personnel Psychology, 41(3), 457-479. https://doi.org/10.1111/j.1744-6570.1988. tb00638.x

Onyeador, I. N., Hudson, S. K. T., \& Lewis, N. A., Jr. (2021). Moving beyond implicit bias training: Policy insights for increasing organizational diversity. Policy Insights from the Behavioral and Brain Sciences, 8(1), 19-26. https://doi.org/10.1177/2372732220983840

Petty, R. E., \& Cacioppo, J. T. (1986). The Elaboration Likelihood Model of Persuasion. In R. E. Petty \& J. T. Cacioppo (Eds.), Communication and Persuasion: Central and Peripheral Routes to Attitude Change (pp. 1-24). Springer. https://doi.org/10.1007/ 978-1-4612-4964-1_1

Pfund, C., Miller, S., Brenner, K., Bruns, P., Chang, A., Ebert-May, D., ... \& Handelsman, J. (2009). Summer institute to improve university science teaching. Science, 324(5926), 470-471. https://doi.org/10.1126/science.1170015

Pfund C., Spencer K. C., Asquith P., House S. C., Miller S., \& Sorkness C. A. (2015). Building national capacity for research mentor training: An evidence-based approach to training the trainers. $C B E-$ Life Sciences Education, 14(2), ar24. https://doi.org/10.1187/cbe. 14-10-0184

Pietri, E. S., Drawbaugh, M. L., Lewis, A. N., \& Johnson, I. R. (2019). Who encourages Latina women to feel a sense of identity-safety in STEM environments? Journal of Experimental Social Psychology, 84, 103827. https://doi.org/10.1016/j.jesp.2019.103827

Pietri, E. S., Johnson, I. R., Majid, S., \& Chu, C. (2020). Seeing What's Possible: Videos are more Effective than Written Portrayals for Enhancing the Relatability of Scientists and Promoting Black Female Students' Interest in STEM. Sex Roles, 84(7-8), 14-33. https://doi.org/10.1007/s11199-020-01153-x

Pietri, E. S., Johnson, I. R., \& Ozgumus, E. (2018a). One size may not fit all: Exploring how the intersection of race and gender and stigma consciousness predict effective identity-safe cues for Black women. Journal of Experimental Social Psychology, 74, 291-306. https://doi.org/10.1016/j.jesp.2017.06.021

Pietri, E. S., Johnson, I. R., Ozgumus, E., \& Young, A. I. (2018b). Maybe she is relatable: Increasing women's awareness of gender bias encourages their identification with women scientists. Psychology of Women Quarterly, 42(2), 192-219. https://doi.org/10. $1177 / 0361684317752643$

Plant, E. A., \& Devine, P. G. (1998). Internal and external motivation to respond without prejudice. Journal of Personality and Social Psychology, 75(3), 811-832. https://doi.org/10.1037/0022-3514. 75.3.811

Plant, E. A., \& Devine, P. G. (2001). Responses to Other-Imposed Pro-Black Pressure: Acceptance or Backlash? Journal of Experimental Social Psychology, 37(6), 486-501. https://doi.org/10. 1006/jesp.2001.1478

Point, S., \& Singh, V. (2003). Defining and Dimensionalising Diversity: Evidence from Corporate Websites across Europe. European Management Journal, 21(6), 750-761. https://doi.org/10. 1016/j.emj.2003.09.015
Purdie-Vaughns, V., Steele, C. M., Davies, P. G., Ditlmann, R., \& Crosby, J. R. (2008). Social identity contingencies: How diversity cues signal threat or safety for African Americans in mainstream institutions. Journal of Personality and Social Psychology, 94(4), 615-630. https://doi.org/10.1037/0022-3514.94.4.615

Ragins, B. R., \& Cotton, J. L. (1999). Mentor functions and outcomes: A comparison of men and women in formal and informal mentoring relationships. Journal of Applied Psychology, 84(4), 529500. https://doi.org/10.1037/0021-9010.84.4.529

Rainey, K., Dancy, M., Mickelson, R., Stearns, E., \& Moller, S. (2018). Race and gender differences in how sense of belonging influences decisions to major in STEM. International Journal of STEM Education, 5(10), 1-14. https://doi.org/10.1186/ s40594-018-0115-6

Remedios, J. D., \& Snyder, S. H. (2015). How Women of Color Detect and Respond to Multiple Forms of Prejudice. Sex Roles, 73(9), 371-383. https://doi.org/10.1007/s11199-015-0453-5

Rosette, A. S., Koval, C. Z., Ma, A., \& Livingston, R. (2016). Race matters for women leaders: Intersectional effects on agentic deficiencies and penalties. The Leadership Quarterly, 27(3), 429-445.

Rosette, A. S., \& Livingston, R. W. (2012). Failure is not an option for Black women: Effects of organizational performance on leaders with single versus dual-subordinate identities. Journal of Experimental Social Psychology, 48(5), 1162-1167.

Sesko, A. K., \& Biernat, M. (2010). Prototypes of race and gender: The invisibility of Black women. Journal of Experimental Social Psychology, 46(2), 356-360. https://doi.org/10.1016/j.jesp.2009. 10.016

Settles, I. H. (2006). Use of an Intersectional Framework to Understand Black Women's Racial and Gender Identities. Sex Roles, 54(9), 589-601. https://doi.org/10.1007/s11199-006-9029-8

Steele, C. M., Spencer, S. J., \& Aronson, J. (2002). Contending with group image: The psychology of stereotype and social identity threat. In Advances in Experimental Social Psychology (Vol. 34, pp. 379-440). Academic Press. https://doi.org/10.1016/S00652601(02)80009-0

Stout, J. G., Dasgupta, N., Hunsinger, M., \& McManus, M. A. (2011). STEMing the tide: Using ingroup experts to inoculate women's self-concept in science, technology, engineering, and mathematics (STEM). Journal of Personality and Social Psychology, 100(2), 255-270. https://doi.org/10.1037/a0021385

Tingley, D., Yamamoto, T., Hirose, K., Keele, L., Imai, K., \& Yamamoto, M. T. (2019). Package 'mediation'. https://imai.princeton.edu/ projects/mechanisms.html

Turner, C. S. V., González, J. C., \& Wood, J. L. (2008). Faculty of color in academe: What 20 years of literature tells us. Journal of Diversity in Higher Education, 1(3), 139-168. https://doi.org/ 10.1037/a0012837

U.S. Bureau of Labor Statistics. (2018). Labor force characteristics by race and ethnicity. Retrieved June, 2020, from https://www.bls. gov/opub/reports/race-and-ethnicity/2018/home.htm

Van Hoye, G., \& Lievens, F. (2007). Investigating web-based recruitment sources: Employee testimonials vs word-of-mouse. International Journal of Selection and Assessment, 15(4), 372-382. https://doi.org/10.1111/j.1468-2389.2007.00396.x

Walker, H. J., Field, H. S., Giles, W. F., \& Armenakis, A. A. B. (2009). Displaying employee testimonials on recruitment webs sites: Effects of communication media, employee race, and job seeker race on organizational attraction and information credibility. Journal of Applied Psychology, 94(5), 1354-1364. https://doi.org/10. 1037/a0014964

Walster, E., Aronson, E., \& Abrahams, D. (1966). On increasing the persuasiveness of a low prestige communicator. Journal of Experimental Social Psychology, 2(4), 325-342. https://doi.org/10.1016/ 0022-1031(66)90026-6 
Walton, G. M., \& Cohen, G. L. (2007). A question of belonging: Race, social fit, and achievement. Journal of Personality and Social Psychology, 92(1), 82-96. https://doi.org/10.1037/0022-3514. 92.1.82

Walton, G. M., \& Cohen, G. L. (2011). A brief social-belonging intervention improves academic and health outcomes of minority students. Science, 331(6023), 1447-1451. https://doi.org/10.1126/ science. 1198364

Walton, G. M., Murphy, M. C., \& Ryan, A. M. (2015). Stereotype Threat in Organizations: Implications for Equity and Performance. Annual Review of Organizational Psychology and Organizational Behavior, 2(1), 523-550. https://doi.org/10. 1146/annurev-orgpsych-032414-111322

Walton, G. M., \& Yeager, D. S. (2020). Seed and soil: Psychological affordances in contexts help to explain where wise interventions succeed or fail. Current Directions in Psychological Science, 29(3), 219-226. https://doi.org/10.1177/0963721420904453

Warner, L. R. (2008). A best practices guide to intersectional approaches in psychological research. Sex Roles, 59, 454-463. https://doi.org/10.1007/s11199-008-9504-5
Williams, J., Phillips, K. W., \& Hall, E. V. (2014). Double jeopardy?: Gender bias against women of color in science. Hastings College of the Law, Center for WorkLife Law. https://worklifelaw. org/publications/Double-Jeopardy-Report_v6_full_web-sm.pdf

Wilton, L. S., Bell, A. N., Vahradyan, M., \& Kaiser, C. R. (2020). Show Don't Tell: Diversity Dishonesty Harms Racial/Ethnic Minorities at Work. Personality and Social Psychology Bulletin, Article 0146167219897149. https://doi.org/10.1177/0146167219897149

Windscheid, L., Bowes-Sperry, L., Kidder, D. L., Cheung, H. K., Morner, M., \& Lievens, F. (2016). Actions speak louder than words: Outsiders' perceptions of diversity mixed messages. Journal of Applied Psychology, 101(9), 1329-1341. https://doi.org/ 10.1037/ap10000107

Publisher's Note Springer Nature remains neutral with regard to jurisdictional claims in published maps and institutional affiliations. 